\title{
In bargaining we trust
}

Citation for published version (APA):

Saran, R. R. S. (2007). In bargaining we trust. METEOR, Maastricht University School of Business and Economics. METEOR Research Memorandum No. 048 https://doi.org/10.26481/umamet.2007048

Document status and date:

Published: 01/01/2007

DOI:

10.26481/umamet.2007048

Document Version:

Publisher's PDF, also known as Version of record

\section{Please check the document version of this publication:}

- A submitted manuscript is the version of the article upon submission and before peer-review. There can be important differences between the submitted version and the official published version of record.

People interested in the research are advised to contact the author for the final version of the publication, or visit the DOI to the publisher's website.

- The final author version and the galley proof are versions of the publication after peer review.

- The final published version features the final layout of the paper including the volume, issue and page numbers.

Link to publication

\footnotetext{
General rights rights.

- You may freely distribute the URL identifying the publication in the public portal. please follow below link for the End User Agreement:

www.umlib.nl/taverne-license

Take down policy

If you believe that this document breaches copyright please contact us at:

repository@maastrichtuniversity.nl

providing details and we will investigate your claim.
}

Copyright and moral rights for the publications made accessible in the public portal are retained by the authors and/or other copyright owners and it is a condition of accessing publications that users recognise and abide by the legal requirements associated with these

- Users may download and print one copy of any publication from the public portal for the purpose of private study or research.

- You may not further distribute the material or use it for any profit-making activity or commercial gain

If the publication is distributed under the terms of Article $25 \mathrm{fa}$ of the Dutch Copyright Act, indicated by the "Taverne" license above, 
Rene Saran

In Bargaining We Trust

$\mathrm{RM} / 07 / 048$

JEL code: C78, D82

\section{METE@R}

Maastricht research school of Economics of TEchnology and ORganizations

Universiteit Maastricht

Faculty of Economics and Business Administration P.O. Box 616

NL - 6200 MD Maastricht

phone : ++31433883830

fax : ++31433884873 


\title{
In Bargaining We Trust*
}

\author{
Rene $\operatorname{Saran}^{\dagger}$ \\ Maastricht University, Maastricht, The Netherlands \\ This version: September 2007
}

\begin{abstract}
We introduce trustworthy traders in bilateral trading. Trustworthy traders do not misrepresent their private information. We prove that an increase in the levels of trust (probabilities that traders are trustworthy) can reduce the maximum attainable probability of trade among the strategic traders in the set of $k$-double auctions. In contrast, if the levels of trust increase, then we can construct direct mechanisms with a higher probability of trade among the strategic traders. In fact, there exist expost efficient direct mechanisms if the levels of trust are high but $k$-double auctions are inefficient for all levels of trust. We prove that $k$-double auctions are constraintinefficient for generic levels of trust when players have uniform priors.
\end{abstract}

Keywords: Bilateral Trading; Trust; Direct Mechanisms; $k$-Double Auctions; Probability of Trade; Ex-post Efficiency

JEL: C78; D82

*This paper is based on Chapter 3 of my Ph.D dissertation (Brown University, 2007). I am indebted to my advisor Roberto Serrano for his guidance and suggestions throughout the project - and the title. I am also grateful to Pedro Dal Bó, Allan Feldman, Glenn Loury, Sergio Turner and seminar audiences at Brown Univ., Maastricht Univ., 17th International Conference on Game Theory (Stony Brook) and LAMES 2006 (Mexico City) for their comments and suggestions.

${ }^{\dagger}$ Email address: r.saran@algec.unimaas.nl; Tel: +31-43-3883763; Fax: +31-43-3884878 


\section{Introduction}

Experiments have documented departures from the paradigm of Homo Economicus, leading economists to acknowledge the existence of non-strategic or behavioral-type players. This has generated a line of inquiry into the "incentives" for the survival of behavioral-type players. However, economists have rightly not jettisoned Homo Economicus for good; after all, humans have the ability to comprehend and reason. Studying the implications of strategic behavior while simultaneously acknowledging the existence of behavioral types points to another line of inquiry that we can pursue: how is the behavior of the strategic-type players affected by the possibility of interacting with the behavioral-type players? With such a motivation, we introduce trustworthy-type traders in bilateral trading and study the level of efficiency attained by the strategic-type traders when they are uncertain about each others trustworthiness.

Trust, a belief in the trustworthiness of others, is a crucial factor in all economic interactions that take place when there is incomplete information. ${ }^{1}$ This is also true of bargaining because private information of individuals, which is mostly not verifiable (e.g., valuation of an object), makes the gains that can be achieved through negotiations uncertain. In such circumstances, there exist opportunities for individuals to mislead others, for instance, by making false claims ("Certainly I cannot accept this offer, it costs me more than that!"). Such misrepresentations, indeed even the existence of the opportunity to misrepresent, have been proved to generate inefficiencies in economic interactions - $[2,15]$. However, a simple introspection would prove that most of us do not believe that this world is inhabited by cheaters; after all, we all have at one point or other met someone who is trustworthy, a person who can "....be relied on as honest, truthful, or reliable." 2

\footnotetext{
${ }^{1}$ Hardin [8] stresses the relationship between trust and trustworthiness of an individual. Dasgupta [4] and Gambetta [6] define trust as a belief over actions of others. Good [7] says that trust is based on claims made by individuals.

${ }^{2}$ Pearsall [16, pg. 1540].
} 
We consider the bilateral trading problem in which a buyer and a seller of an indivisible object engage in a trading mechanism that determines whether they trade and at what price. Each player is privately informed about her valuation for the object but does not know the valuation of the other player; she only knows the latter's distribution. Moreover, each player can be of either trustworthy disposition or strategic disposition. A player privately knows her disposition but does not know the disposition of the other player. The buyer believes that the seller is trustworthy type with probability $\epsilon_{s}$ while the seller believes that the buyer is trustworthy type with probability $\epsilon_{b}$. These probabilities reflect the levels of trust in the trading problem. We study how the levels of trust affects the probability of trade among the strategic types in two sets of trading mechanisms, the set of direct mechanisms and the set of $k$-double auctions. ${ }^{3}$

In context of the trading problem studied here, a player is trustworthy type if she does not cause any strategic impediment to trade by manipulating her private information. In a direct mechanism, players are required to submit reports about their respective types. For a direct mechanism, we assume that the trustworthy-type player reports her type truthfully. It must be emphasized that since the type of a player has two components, valuation type and disposition type, the trustworthy-type player will truthfully report both these components. A $k$-double auction is another trading mechanism that has been extensively studied both theoretically and experimentally due to its similarity to real world bargaining procedures. ${ }^{4}$ In the $k$-double auction, players simultaneously submit sealed bids and trade takes place if and only if the buyer's bid exceeds the seller's bid at a price equal to the weighted average of the two bids with the weight of $k$ on the buyer's bid. For this trading mechanism, we assume that the trustworthy-type player bids truthfully, that is, she bids equal to her valuation. ${ }^{5}$

\footnotetext{
${ }^{3}$ None of the results will change if we were to instead study the effect of the levels of trust on the ex-ante gains from trade obtained in the event that both players are strategic type.

${ }^{4}$ For theoretical analysis see Chatterjee and Samuelson [3], Farrell and Gibbons [5], Mathews and Postlewaite [12], Leininger et al. [11] and Satterthwaite and Williams [19]. Radner and Schotter [17], Valley et al. [21] and McGinn et al. [13] conduct experiments on the $k$-double auction.

${ }^{5}$ It could be argued that naming these traders honest or truth-telling type would better reflect the
} 
In fact, these assumptions about the trustworthy types are motivated by the behavior of players observed in experiments on $\frac{1}{2}$-double auctions conducted by Valley et al. [21] and McGinn et al. [13]. ${ }^{6}$

A common perception is that trust among individuals involved in any interaction is better for their welfare. We challenge this perception by proving that higher levels of trust can reduce the probability of trade among the strategic-type traders in the set of $k$-double auctions. To be precise, we consider a bilateral trading problem in which the valuations are distributed uniformly and independently on $[0,1]$. We prove that if the levels of trust are positive, then the probability of trade among the strategic-type traders in any equilibrium outcome of any $k$-double auction is strictly less than the maximum probability of trade that can be achieved in the set of $k$-double auctions when the traders completely distrust each other. Intuitively, the strategic types try to capitalize on the trustworthy types' honesty by bidding "tougher" so that the strategic-type buyer bids lower and the strategic-type seller bids higher "on average" - the proof does not rely on this intuition though. Hence, any mediator/mechanism designer whose goal is to maximize the probability of trade among the strategic types will be strictly "worse-off" if the players trust each other and this is true even if she could choose any trading mechanism for the players from the set of $k$-double auctions. This result suggests that trust need not always be welfare improving.

Fortunately, such negative consequences of trust can be completely eliminated by designing "correct" mechanisms. In the statement of the above mentioned negative result, we assumptions that we make about their behavior in the two mechanisms. Such a name would imply that these traders have some psychological or moral bias for telling the truth. However, there could be other reasons for the players to not manipulate their private information. For instance, Saran and Serrano [18] provide an evolutionary explanation of truthful bidding in $k$-double auctions which is because of the presence of a friction to change one's bid. Moreover, we do not assume that the trustworthy-type traders bid truthfully in the $k$-double auction when they are allowed to communicate before bargaining (see Assumption 4.6).

${ }^{6}$ For instance, McGinn et al. [13] find over 50\% of individual communications in which players revealed their valuation types truthfully when they were allowed to communicate before bargaining. McGinn et al. [13] also find players bidding truthfully both when allowed to communicate (30\% of individual bids) and when not allowed to communicate (44\% of individual bids) before the double auction. 
restricted ourselves to the set of $k$-double auctions, which is a subset of the set of direct mechanisms since the revelation principle still holds. We prove that if we can use direct mechanisms, then for all bilateral trading problems, any increase in the levels of trust is weakly better. This is because we can design new incentive compatible and individually rational direct mechanisms with at least as high probability of trade among the strategic types as before. ${ }^{7}$ Thus, more flexibility of design available in the set of direct mechanisms compared to that in the set of $k$-double auctions can be used to create incentives for the strategic types so that any increase in the levels of trust weakly improves the efficiency attained by them.

By juxtaposing these results for the sets of $k$-double auctions and direct mechanisms, we conclude that $k$-double auctions are constraint-inefficient for generic levels of trust in the bilateral trading problem with uniform priors on the valuation type. Myerson and Satterthwaite [15] prove that if both the players are only strategic type, then a $\frac{1}{2}$-double auction is constraint-efficient in the bilateral trading problem with uniform priors. Hence, the constraint-efficiency of the set of $k$-double auctions is not robust to perturbations in the disposition type of the players. ${ }^{8}$

The positive influence of the levels of trust on the efficiency of trade among the strategic types in the set of direct mechanisms prompts an inquiry into the "limit" of this positive effect, that is, can we achieve ex-post efficiency in the set of direct mechanisms? The answer is yes. For any bilateral trading problem, there exist ex-post efficient, incentive compatible and individually rational direct mechanisms if and only if at least one player has high enough trust in the other player. $^{9}$ In contrast, Myerson and Satterthwaite [15] prove that if the

\footnotetext{
${ }^{7}$ Incentive compatibility for the trustworthy types is trivially satisfied since they report truthfully. Also, by individual rationality we mean interim individual rationality.

${ }^{8}$ In a similar vein, Satterthwaite and Williams [19] prove that if the players are only strategic type, then the constraint-efficiency of the set of $k$-double auctions is not robust to perturbations in the distributions of the players' valuations.

${ }^{9}$ Ex-post efficiency is attained not only in the event that both players are strategic type but in any realization of disposition types.
} 
players are only strategic type, then for all bilateral trading problems, there do not exist ex-post efficient mechanisms that are also incentive compatible and individually rational. Thus, relaxation of the incentive compatibility constraints for a substantial "proportion of the population" implied by a high enough probability of trustworthy types has important implications for efficiency. We also show that trust among the players is substitutable, that is, the more one player trusts the other, the less the latter needs to trust the former in order to attain ex-post efficiency using an incentive compatible and individually rational direct mechanism.

To understand the intuition behind this result, note that the trustworthy types do not impose any "cost" of eliciting private information on the mechanism and more importantly, generate positive ex-ante gains from trade by being truthful in communicating their type. If one player has high enough trust in the other player, the "cost" of eliciting private information from the strategic types is less than the ex-ante gains from trade generated by the trustworthy types in any ex-post efficient mechanism. When this happens, we can construct ex-post efficient direct mechanisms that induce the strategic types to both reveal their type truthfully and voluntarily participate in the mechanism. This is done by providing enough subsidy to the strategic types through lump-sum transfers of the ex-ante gains from trade generated by the trustworthy types. The amount transferred from the trustworthy types is equal to the gains generated by them and therefore, the trustworthy types also satisfy their individual rationality constraints.

$k$-double auctions, however, are shown to be inefficient for all positive levels of trust (except when at least one player is for sure trustworthy type). In $k$-double auctions, the trustworthy types bid truthfully and hence do not impose any "cost" of eliciting private information. However, the pricing rule of $k$-double auctions does not ensure that enough subsidy is provided to the strategic types. Since trade takes place at a weighted average of the two bids, the trustworthy types are able to retain ample gains from trade that are 
generated by them. Even any form of communication between the players before they play any $k$-double auction will be fruitless in getting ex-post efficiency. As long as the trustworthy types bid "rationally" (that is, the trustworthy type of the buyer (seller) bids at most (at least) her valuation), any $k$-double auction with any form of pre-play communication will be unable to produce adequate amount of subsidy for the strategic types and thus remain ex-post inefficient.

The fact that we can get ex-post efficiency using direct mechanisms but not $k$-double auctions shows the importance of designing correct transfer payments from the trustworthy types to the strategic types in order to induce the latter to reveal their private information, which can be done by using direct mechanisms but not $k$-double auctions. The real world trading mechanisms like $k$-double auctions are thus not well designed from the perspective of achieving efficiency by adequately capitalizing on the trust among players.

This paper is related to the literature on reputation beginning with the seminal papers of Kreps et al. [9], Kreps and Wilson [10] and Milgrom and Roberts [14]. Sobel [20] studies the effect of introducing a honest-type sender in a model of strategic information transmission and Dasgupta [4] studies the influence of a honest-type salesman in the market for lemons. Abreu and Gul [1] study the effect of adding a behavioral type, who is obstinate in its demands and offers, on bargaining outcomes. Nevertheless, it must be emphasized that this paper does not focus on the issue of the strategic-type players building a reputation of being trustworthy type in a repeated interaction.

This paper is organized as follows. Section 2 outlines the bilateral trading problem and the assumptions about the trustworthy disposition. Subsection 2.1 provides the necessary conditions for a trading mechanism to satisfy incentive compatibility and individual rationality. Subsection 2.2 lists the sufficient conditions for a direct mechanism to satisfy incentive compatibility and individual rationality. Section 3 shows how an increase in the levels of trust can reduce efficiency in the set of $k$-double auctions but can be used to improve effi- 
ciency in the set of direct mechanisms. Section 4 shows that it is possible to attain ex-post efficiency using direct mechanisms if the levels of trust are high enough but this is impossible if we restrict ourselves to the set $k$-double auctions with or without any form of pre-play communication. Then we conclude and in the final section present the proofs of the results.

\section{Bilateral Trading Problem}

A buyer (denoted by $b$ ) and a seller (denoted by $s$ ) engage in a trading mechanism to trade an indivisible good. Each player $i$, where $i=b, s$, can have two possible dispositions $\left(d_{i}\right)$, trustworthy $(t r)$ and strategic $(s t)$. The probability that player $i$ is trustworthy type is $\epsilon_{i}$, which is independent of the other player's valuation and disposition. Valuations of the strategic and trustworthy types of the buyer are distributed on some interval $\left[\underline{a}_{b}, \bar{a}_{b}\right]$ independently of the seller's valuation and disposition. Valuations of the strategic and trustworthy types of the seller are distributed on $\left[\underline{a}_{s}, \bar{a}_{s}\right]$ independently of the buyer's valuation and disposition. Let $F_{d_{i}}, i=b, s \& d_{i}=t r, s t$, be the distributions of valuations. The associated density functions $f_{d_{i}}$ are continuous and positive on their respective domains. Players know only

their own type $\left(v_{i}, d_{i}\right)$. All other information is common knowledge. $\left(\epsilon_{i}, F_{s t_{i}}, F_{t r_{i}}\right)_{i=b, s}$ defines a bilateral trading problem. We term $\epsilon_{b}$ and $\epsilon_{s}$ as the levels of trust.

Trustworthy types do not misrepresent their private information in ways that is detrimental to trade. But that does not mean that they are "irrational" in the sense that they are willing to participate in a trading mechanism even if their expected payoff is less than their outside option (opportunity cost of participation), which for convenience is equal to 0 for all types of all players. This motivates the following assumptions about the trustworthy types.

\section{Assumption 2.1. Assumptions about Trustworthy Types:}

1. A trustworthy type answers truthfully whenever she is asked to about her type (valu- 
ation or disposition).

2. Consider a trading mechanism in which players have to submit sealed bids for the object. A trustworthy type bids equal to her valuation if she has not entered into an agreement with the other player prior to submitting her bid.

3. A trustworthy type voluntarily participates in a trading mechanism only if her expected payoff from participation is non-negative.

A consequence of the first assumption is that in a direct trading mechanism in which players are asked to report their respective types, the trustworthy-type player will report her type truthfully. The second assumption implies that in a $k$-double auction, the trustworthy type bids equal to her valuation. Shading by the buyer or exaggeration by the seller is a misrepresentation of her private information and reduces the likelihood of trade. Finally, the last assumption above implies individual rationality for the trustworthy types.

An outcome of a trading mechanism is an allocation rule that specifies the following for all pairs of valuation types $\left(v_{b}, v_{s}\right)$ :

1. Probability of trade:

- if both players are strategic, $p_{(s t, s t)}\left(v_{b}, v_{s}\right)$.

- if only the buyer is strategic, $p_{(s t, t r)}\left(v_{b}, v_{s}\right)$.

- if only the seller is strategic, $p_{(t r, s t)}\left(v_{b}, v_{s}\right)$.

- if both players are trustworthy, $p_{(t r, t r)}\left(v_{b}, v_{s}\right)$.

2. Payment from the buyer to the seller:

- if both players are strategic, $x_{(s t, s t)}\left(v_{b}, v_{s}\right)$.

- if only the buyer is strategic, $x_{(s t, t r)}\left(v_{b}, v_{s}\right)$. 
- if only the seller is strategic, $x_{(t r, s t)}\left(v_{b}, v_{s}\right)$.

- if both players are trustworthy, $x_{(t r, t r)}\left(v_{b}, v_{s}\right)$.

Define the following for all types $\left(v_{i}, d_{i}\right),{ }^{10}$

$$
\begin{aligned}
& \bar{p}_{\left(b, d_{b}\right)}\left(v_{b}\right) \equiv\left(1-\epsilon_{s}\right) \int_{\left[\underline{a}_{s}, \bar{a}_{s}\right]} p_{\left(d_{b}, s t\right)}\left(v_{b}, v_{s}\right) f_{s t_{s}} d v_{s}+\epsilon_{s} \int_{\left[\underline{a}_{s}, \bar{a}_{s}\right]} p_{\left(d_{b}, t r\right)}\left(v_{b}, v_{s}\right) f_{t r_{s}} d v_{s} \\
& \bar{p}_{\left(s, d_{s}\right)}\left(v_{s}\right) \equiv\left(1-\epsilon_{b}\right) \int_{\left[\underline{a}_{b}, \bar{a}_{b}\right]} p_{\left(s t, d_{s}\right)}\left(v_{b}, v_{s}\right) f_{s t_{b}} d v_{b}+\epsilon_{b} \int_{\left[\underline{a}_{b}, \bar{a}_{b}\right]} p_{\left(t r, d_{s}\right)}\left(v_{b}, v_{s}\right) f_{t r_{b}} d v_{b} \\
& \bar{x}_{\left(b, d_{b}\right)}\left(v_{b}\right) \equiv\left(1-\epsilon_{s}\right) \int_{\left[\underline{a}_{s}, \bar{a}_{s}\right]} x_{\left(d_{b}, s t\right)}\left(v_{b}, v_{s}\right) f_{s t_{s}} d v_{s}+\epsilon_{s} \int_{\left[\underline{a}_{s}, \bar{a}_{s}\right]} x_{\left(d_{b}, t r\right)}\left(v_{b}, v_{s}\right) f_{t r_{s}} d v_{s} \\
& \bar{x}_{\left(s, d_{s}\right)}\left(v_{s}\right) \equiv\left(1-\epsilon_{b}\right) \int_{\left[\underline{a}_{b}, \bar{a}_{b}\right]} x_{\left(s t, d_{s}\right)}\left(v_{b}, v_{s}\right) f_{s t_{b}} d v_{b}+\epsilon_{b} \int_{\left[\underline{a}_{b}, \bar{a}_{b}\right]} x_{\left(t r, d_{s}\right)}\left(v_{b}, v_{s}\right) f_{t r_{b}} d v_{b}
\end{aligned}
$$

Payoffs of the players for any given outcome of a trading mechanism are:

$$
\begin{gathered}
U_{\left(b, d_{b}\right)}\left(v_{b}\right)=v_{b} \bar{p}_{\left(b, d_{b}\right)}\left(v_{b}\right)-\bar{x}_{\left(b, d_{b}\right)}\left(v_{b}\right) \\
U_{\left(s, d_{s}\right)}\left(v_{s}\right)=\bar{x}_{\left(s, d_{s}\right)}\left(v_{s}\right)-v_{s} \bar{p}_{\left(s, d_{s}\right)}\left(v_{s}\right)
\end{gathered}
$$

Definition 2.2. $I C^{*}$ : An outcome of a trading mechanism is incentive compatible* for the strategic types if

$$
\begin{aligned}
& U_{(b, s t)}\left(v_{b}\right) \geq v_{b} \bar{p}_{(b, s t)}\left(v_{b}^{\prime}\right)-\bar{x}_{(b, s t)}\left(v_{b}^{\prime}\right), \forall v_{b}, v_{b}^{\prime} \\
& U_{(s, s t)}\left(v_{s}\right) \geq \bar{x}_{(s, s t)}\left(v_{s}^{\prime}\right)-v_{s} \bar{p}_{(s, s t)}\left(v_{s}^{\prime}\right), \forall v_{s}, v_{s}^{\prime} .
\end{aligned}
$$

Any Bayesian-Nash equilibrium outcome of a trading mechanism will satisfy $I C^{*}$, otherwise some valuation type of a strategic-type player will prefer to imitate the strategy of another valuation type of that strategic-type player.

If the players are only strategic type, then $I C^{*}$ is the only incentive constraint that will

\footnotetext{
${ }^{10}$ We sometimes drop the argument $v_{i}$ of the function $f_{d_{i}}$ to simplify notation.
} 
be satisfied by a Bayesian-Nash equilibrium outcome of a trading mechanism. However, now that the problem also has the trustworthy-type players, it must also be that in equilibrium, any valuation type of a strategic-type player does not want to imitate the strategy of any valuation type of the trustworthy type of that player. Thus, any Bayesian-Nash equilibrium outcome of a trading mechanism will satisfy incentive compatibility $(I C)$ defined below.

Definition 2.3. $I C$ : An outcome of a trading mechanism is incentive compatible for the strategic types if it is $I C^{*}$ and

$$
\begin{aligned}
& U_{(b, s t)}\left(v_{b}\right) \geq v_{b} \bar{p}_{(b, t r)}\left(v_{b}^{\prime}\right)-\bar{x}_{(b, t r)}\left(v_{b}^{\prime}\right), \forall v_{b}, v_{b}^{\prime} \\
& U_{(s, s t)}\left(v_{s}\right) \geq \bar{x}_{(s, t r)}\left(v_{s}^{\prime}\right)-v_{s} \bar{p}_{(s, t r)}\left(v_{s}^{\prime}\right), \forall v_{s}, v_{s}^{\prime}
\end{aligned}
$$

Thus, although adding the trustworthy types to the problem relaxes the incentive constraints for a proportion of the players (i.e., the trustworthy types), it also adds to the total number of incentive constraints in the problem.

Definition 2.4. IR: An outcome of a trading mechanism is individually rational if $\forall i$,

$$
U_{\left(i, d_{i}\right)}\left(v_{i}\right) \geq 0, \forall\left(v_{i}, d_{i}\right)
$$

$I R$ says that all types of all players get non-negative payoffs. Any Bayesian-Nash equilibrium outcome a trading mechanism will satisfy $I R$ since the outside option for all types of all players is equal to 0 .

\subsection{Necessary Conditions for $I C$ and $I R$ Mechanisms}

The following lemma gives the necessary conditions that any $I C^{*}$ (and thus any $I C$ ) outcome of a trading mechanism will satisfy.

Lemma 2.5. For any $I C^{*}$ outcome of a trading mechanism it must be that: 
1. $\bar{p}_{(b, s t)}\left(v_{b}\right)$ is weakly increasing and $\bar{p}_{(s, s t)}\left(v_{s}\right)$ is weakly decreasing.

2. $U_{(b, s t)}\left(v_{b}\right)=U_{(b, s t)}\left(\underline{a}_{b}\right)+\int_{\left[\underline{a}_{b}, v_{b}\right]} \bar{p}_{(b, s t)}\left(y_{b}\right) d y_{b}$.

3. $U_{(s, s t)}\left(v_{s}\right)=U_{(s, s t)}\left(\bar{a}_{s}\right)+\int_{\left[v_{s}, \bar{a}_{s}\right]} \bar{p}_{(s, s t)}\left(y_{s}\right) d y_{s}$.

4. The following equality holds:

$$
\begin{aligned}
& \left(1-\epsilon_{b}\right)\left(1-\epsilon_{s}\right) \int_{\left[\underline{a}_{b}, \bar{a}_{b}\right]} \int_{\left[\underline{a}_{s}, \bar{a}_{s}\right]}\left(\left[v_{b}-\frac{1-F_{s t_{b}}\left(v_{b}\right)}{f_{s t_{b}}\left(v_{b}\right)}\right]-\left[v_{s}+\frac{F_{s t_{s}}\left(v_{s}\right)}{f_{s t_{s}}\left(v_{s}\right)}\right]\right) p_{(s t, s t)}\left(v_{b}, v_{s}\right) f_{s t_{s}} f_{s t_{b}} d v_{s} d v_{b} \\
& +\epsilon_{b}\left(1-\epsilon_{s}\right) \int_{\left[\underline{a}_{b}, \bar{a}_{b}\right]} \int_{\left[\underline{a}_{s}, \bar{a}_{s}\right]}\left(v_{b}-\left[v_{s}+\frac{F_{s t_{s}}\left(v_{s}\right)}{f_{s t_{s}}\left(v_{s}\right)}\right]\right) p_{(t r, s t)}\left(v_{b}, v_{s}\right) f_{s t_{s}} f_{t r_{b}} d v_{s} d v_{b} \\
& +\epsilon_{s}\left(1-\epsilon_{b}\right) \int_{\left[\underline{a}_{b}, \bar{a}_{b}\right]} \int_{\left[\underline{a}_{s}, \bar{a}_{s}\right]}\left(\left[v_{b}-\frac{1-F_{s t_{b}}\left(v_{b}\right)}{f_{s t_{b}}\left(v_{b}\right)}\right]-v_{s}\right) p_{(s t, t r)}\left(v_{b}, v_{s}\right) f_{t r_{s}} f_{s t_{b}} d v_{s} d v_{b} \\
& +\epsilon_{b} \epsilon_{s} \int_{\left[\underline{a}_{b}, \bar{a}_{b}\right]} \int_{\left[\underline{a}_{s}, \bar{a}_{s}\right]}\left(v_{b}-v_{s}\right) p_{(t r, t r)}\left(v_{b}, v_{s}\right) f_{t r_{s}} f_{t r_{b}} d v_{s} d v_{b} \\
& =\left(1-\epsilon_{b}\right) U_{(b, s t)}\left(\underline{a}_{b}\right)+\left(1-\epsilon_{s}\right) U_{(s, s t)}\left(\bar{a}_{s}\right)+\epsilon_{b} \int_{\left[\underline{a}_{b}, \bar{a}_{b}\right]} U_{(b, t r)}\left(v_{b}\right) f_{t r_{b}} d v_{b}+\epsilon_{s} \int_{\left[\underline{a}_{s}, \bar{a}_{s}\right]} U_{(s, t r)}\left(v_{s}\right) f_{t r_{s}} d v_{s}
\end{aligned}
$$

The first condition in the lemma is the monotonicity property of the probability of trade functions of the strategic types. It says that a higher valuation type of the strategic-type buyer (seller) must be weakly more (less) likely to trade than a lower valuation type of the strategic-type buyer (seller). Similarly, the second and third conditions in the lemma are the monotonicity properties of the payoffs of the strategic types. More importantly, the second condition implies that any valuation type of the strategic-type buyer with valuation greater than $\underline{a}_{b}$ has to be paid $\int_{\left[\underline{a}_{b}, v_{b}\right]} \bar{p}_{(b, s t)}\left(y_{b}\right) d y_{b}$ more than $U_{(b, s t)}\left(\underline{a}_{b}\right)$ to ensure that she does not imitate the strategy of another valuation type of the strategic-type buyer. Similarly, the third condition says that any valuation type of the strategic-type seller with valuation less than $\bar{a}_{s}$ has to be paid $\int_{\left[v_{s}, \bar{a}_{s}\right]} \bar{p}_{(s, s t)}\left(y_{s}\right) d y_{s}$ more than $U_{(s, s t)}\left(\bar{a}_{s}\right)$ to ensure that she does not imitate the strategy of another valuation type of the strategic-type seller. These extra 
payments can thus be interpreted as the "cost of $I C^{*}$ " on the trading mechanism. Finally, (1) is just an accounting identity, which says that the expected gains from trade minus the expected cost of $I C^{*}$ equals the expected payoff of the players minus the expected cost of $I C^{*}$.

Lemma 2.6. Any outcome of a trading mechanism that satisfies $I C$ and $I R$ must be such that

1. $U_{(b, s t)}\left(v_{b}\right)=U_{(b, s t)}\left(\underline{a}_{b}\right)+\int_{\left[\underline{a}_{b}, v_{b}\right]} \bar{p}_{(b, s t)}\left(y_{b}\right) d y_{b} \geq\left(v_{b}-v_{b}^{\prime}\right) \bar{p}_{(b, t r)}\left(v_{b}^{\prime}\right), \forall v_{b}, v_{b}^{\prime}$.

2. $U_{(b, s t)}\left(v_{s}\right)=U_{(s, s t)}\left(\bar{a}_{s}\right)+\int_{\left[v_{s}, \bar{a}_{s}\right]} \bar{p}_{(s, s t)}\left(y_{s}\right) d y_{s} \geq\left(v_{s}^{\prime}-v_{s}\right) \bar{p}_{(s, t r)}\left(v_{s}^{\prime}\right), \forall v_{s}, v_{s}^{\prime}$.

Individual rationality constraints for the trustworthy types imply that the expected payment of the trustworthy-type buyer with valuation $v_{b}^{\prime}$ cannot exceed $v_{b}^{\prime} \bar{p}_{(b, t r)}\left(v_{b}^{\prime}\right)$ and the expected amount received by the trustworthy-type seller with valuation $v_{s}^{\prime}$ cannot be less than $v_{s}^{\prime} \bar{p}_{(s, t r)}\left(v_{s}^{\prime}\right)$. Thus, we can interpret $\left(v_{b}-v_{b}^{\prime}\right) \bar{p}_{(b, t r)}\left(v_{b}^{\prime}\right)$ as the least possible payoff that the strategic-type buyer with valuation $v_{b}$ could get by imitating the valuation type $v_{b}^{\prime}$ of the trustworthy-type buyer. Similarly, we can interpret $\left(v_{s}^{\prime}-v_{s}\right) \bar{p}_{(s, t r)}\left(v_{s}^{\prime}\right)$ as the least possible payoff that the strategic-type seller with valuation $v_{s}$ could get by imitating the valuation type $v_{s}^{\prime}$ of the trustworthy-type seller. Lemma 2.6 says that a necessary condition for an outcome of a trading mechanism to satisfy $I C$ and $I R$ is that the payoff of any strategic-type player with valuation type $v_{i}$ must be at least equal to the least possible payoff that she could get by imitating any valuation type $v_{i}^{\prime}$ of the trustworthy type of that player.

\subsection{Sufficient Conditions for $I C$ and $I R$ Direct Mechanisms}

A direct mechanism is such that each player is asked to report her type, $\left(v_{i}, d_{i}\right)$, and for each reported pair of types, it specifies an outcome. Hence, we can identify a direct mechanism with its outcome. Trustworthy-type players send truthful reports. Therefore, any direct 
mechanism that satisfies $I C$ is such that truth-telling by all types of both players is a Bayesian-Nash equilibrium.

Note that the revelation principle still holds since any Bayesian-Nash equilibrium outcome of any trading mechanism must satisfy $I C$ and trustworthy types report their type truthfully in a direct mechanism.

The next proposition gives conditions on the probability of trade functions that are sufficient to construct a direct mechanism that satisfies $I C$ and $I R$.

Proposition 2.7. Suppose $\left(p_{\left(d_{b}, d_{s}\right)}\right) d_{b}=s t, t r ; d_{s}=s t, t r$ are functions from $\left[\underline{a}_{b}, \bar{a}_{b}\right] \times\left[\underline{a}_{s}, \bar{a}_{s}\right]$ to $[0,1]$. If the following four conditions are satisfied, then there exist functions $\left(x_{\left(d_{b}, d_{s}\right)}\right)_{d_{b}=s t, t r ; d_{s}=s t, t r}$ such that $\left(p_{\left(d_{b}, d_{s}\right)}, x_{\left(d_{b}, d_{s}\right)}\right)_{d_{b}=s t, t r ; d_{s}=s t, t r}$ is a direct mechanism that satisfies IC and IR.

1. $\bar{p}_{(b, s t)}\left(v_{b}\right)$ is weakly increasing, $\bar{p}_{(s, s t)}\left(v_{s}\right)$ is weakly decreasing.

2. $\int_{\left[\underline{a}_{b}, v_{b}\right]} \bar{p}_{(b, s t)}\left(y_{b}\right) d y_{b} \geq\left(v_{b}-v_{b}^{\prime}\right) \bar{p}_{(b, t r)}\left(v_{b}^{\prime}\right), \forall v_{b}, v_{b}^{\prime}$.

3. $\int_{\left[v_{s}, \bar{a}_{s}\right]} \bar{p}_{(s, s t)}\left(y_{s}\right) d y_{s} \geq\left(v_{s}^{\prime}-v_{s}\right) \bar{p}_{(s, t r)}\left(v_{s}^{\prime}\right), \forall v_{s}, v_{s}^{\prime}$.

4. The following inequality holds:

$$
\begin{aligned}
& \left(1-\epsilon_{b}\right)\left(1-\epsilon_{s}\right) \int_{\left[\underline{a}_{b}, \bar{a}_{b}\right]} \int_{\left[\underline{a}_{s}, \bar{a}_{s}\right]}\left(\left[v_{b}-\frac{1-F_{s t_{b}}\left(v_{b}\right)}{f_{s t_{b}}\left(v_{b}\right)}\right]-\left[v_{s}+\frac{F_{s t_{s}}\left(v_{s}\right)}{f_{s t_{s}}\left(v_{s}\right)}\right]\right) p_{(s t, s t)}\left(v_{b}, v_{s}\right) f_{s t_{s}} f_{s t_{b}} d v_{s} d v_{b} \\
& +\epsilon_{b}\left(1-\epsilon_{s}\right) \int_{\left[\underline{a}_{b}, \bar{a}_{b}\right]} \int_{\left[\underline{a}_{s}, \bar{a}_{s}\right]}\left(v_{b}-\left[v_{s}+\frac{F_{s t_{s}}\left(v_{s}\right)}{f_{s t_{s}}\left(v_{s}\right)}\right]\right) p_{(t r, s t)}\left(v_{b}, v_{s}\right) f_{s t_{s}} f_{t r_{b}} d v_{s} d v_{b} \\
& +\epsilon_{s}\left(1-\epsilon_{b}\right) \int_{\left[\underline{a}_{b}, \bar{a}_{b}\right]} \int_{\left[\underline{a}_{s}, \bar{a}_{s}\right]}\left(\left[v_{b}-\frac{1-F_{s t_{b}}\left(v_{b}\right)}{f_{s t_{b}}\left(v_{b}\right)}\right]-v_{s}\right) p_{(s t, t r)}\left(v_{b}, v_{s}\right) f_{t r_{s}} f_{s t_{b}} d v_{s} d v_{b} \\
& +\epsilon_{b} \epsilon_{s} \int_{\left[\underline{a}_{b}, \bar{a}_{b}\right]} \int_{\left[\underline{a}_{s}, \bar{a}_{s}\right]}\left(v_{b}-v_{s}\right) p_{(t r, t r)}\left(v_{b}, v_{s}\right) f_{t r_{s}} f_{t r_{b}} d v_{s} d v_{b} \\
& \geq 0
\end{aligned}
$$

The first condition is again the monotonicity property of the probability of trade functions of the strategic types. Only this monotonicity condition is used to construct a set of payment 
functions so that we get a direct mechanism that satisfies $I C^{*}$. These payment functions are constructed so that all the gains from trade generated by the trustworthy types are transferred to the strategic types using lump-sum transfers and thus the trustworthy types are pushed to their individual rationality constraints. Moreover, by construction, the payoff of the lowest valuation type of the strategic-type buyer is equal to 0 . Then (2) implies $I R$ for the strategic types. With $I C^{*}$ and $I R$ satisfied, the second and third conditions in the proposition immediately guarantee $I C$ for the strategic types.

Inequality (2) says that the expected gains from trade minus the expected cost of $I C^{*}$ is non-negative. Of course, this inequality is also a necessary condition for any $I C^{*}$ and $I R$ direct mechanism (follows from (1)). What is interesting is that this inequality is also sufficient for constructing an $I C$ and $I R$ direct mechanism. Why does not the inequality require expected gains from trade minus the "expected cost of $I C$ " to be non-negative? This is because of the second and third conditions in the proposition; whenever these hold, going from an $I C^{*}$ and $I R$ mechanism to an $I C$ and $I R$ mechanism can be achieved for "free" by pushing the trustworthy types to 0 payoffs.

Myerson and Satterthwaite [15] analyze the bilateral trading problem without trustworthy types, that is, $\epsilon_{b}=\epsilon_{s}=0$. So in their setup, $I C^{*}$ is equivalent to $I C$. Myerson and Satterthwaite [15, Theorem 1] shows that the monotonicity property of the probability of trade functions and the expected gains from trade greater than or equal to the expected cost of $I C^{*}$ are both necessary and sufficient for there to exist payment functions that along with the probability of trade functions define an $I R$ and $I C^{*}$ direct mechanism. Here we also have trustworthy types. Although trustworthy types do not themselves add more constraints on the mechanism since they reveal themselves truthfully, their presence provides the strategic types an additional opportunity to misreport their type. Thus, we require more sufficient conditions (the second and third conditions in Proposition 2.7) to stop this kind of misreporting. 


\section{Is More Trust Always Better?}

In this section, we show that whether an increase in the levels of trust increases the probability of trade among the strategic types depends on the trading mechanism. Subsection 3.1 considers a bilateral trading problem with uniform distributions of valuations of all disposition types. In that trading problem, if the levels of trust are positive, then the probability of trade among the strategic types in any equilibrium outcome of any $k$-double auction is lower than the maximum probability of trade that can be achieved using $k$-double auctions when the players completely distrust each other. In contrast, in Subsection 3.2 we prove that if we use direct mechanisms to solve the trading problem, then an increase in the levels of trust is weakly better. This is because then we can design a new direct mechanism that will have at least as high probability of trade among the strategic types as before. In Subsection 3.3, we use these two results to comment on the constraint-inefficiency of $k$-double auctions in the problem with uniform priors on valuations.

\section{$3.1 \quad k$-Double Auction with Uniform Priors}

A $k$-double auction is a trading mechanism in which both players simultaneously submit sealed bids. If the buyer's bid $p_{b}$ is greater than or equal to seller's bid $p_{s}$, then trade takes place at price $k p_{b}+(1-k) p_{s}$, where $k \in[0,1]$; otherwise, there is no trade and no payment by the buyer to the seller.

For a bilateral trading problem with only strategic types and valuations of both players distributed uniformly and independently on [0,1], Myerson and Satterthwaite [15] prove that the maximum ex-ante probability of trade achievable in any equilibrium of any trading

mechanism equals $\frac{9}{32}$. This upper bound is achieved in a $\frac{1}{2}$-double auction when players play the Chatterjee-Samuelson (C-S) linear equilibrium strategies (Chatterjee and Samuelson [3]). Proposition 3.1 proves that when the valuations of all disposition types are distributed 
uniformly and independently on $[0,1]$, then for all positive levels of trust, any Bayesian-Nash equilibrium outcome of any $k$-double auction will have a lower ex-ante probability of trade among strategic types than $\frac{9}{32}$. Thus, higher levels of trust are not necessarily better if the trading mechanisms are in the set of $k$-double auctions.

So for now $\left[\underline{a}_{s}, \bar{a}_{s}\right]=\left[\underline{a}_{b}, \bar{a}_{b}\right]=[0,1]$. Also, $F_{s t_{b}}=F_{s t_{s}}=F_{t r_{b}}=F_{t r_{s}}$ are uniform on $[0,1]$. By assumption, the trustworthy types bid truthfully. Let $\Gamma^{\left(k, \epsilon_{b}, \epsilon_{s}\right)}$ denote the game defined by this trading mechanism.

Proposition 3.1. For all $k \in[0,1]$ and $\left(\epsilon_{b}, \epsilon_{s}\right)$, such that $(0,0) \ll\left(\epsilon_{b}, \epsilon_{s}\right) \ll(1,1)$, the exante probability of trade in the event that both players are strategic type in any equilibrium of $\Gamma^{\left(k, \epsilon_{b}, \epsilon_{s}\right)}$ is less than the the ex-ante probability of trade in the $C$-S equilibrium.

We present an outline of the proof. For a pair $\left(\epsilon_{b}, \epsilon_{s}\right)$, we first define a set of trading outcomes $\mathcal{M}^{\left(\epsilon_{b}, \epsilon_{s}\right)}$ that satisfy certain restrictions. One of these restrictions is that the probability that the strategic-type buyer (seller) trades with the strategic-type seller (buyer) is weakly increasing (decreasing) in the former's valuation. The second step is to show that for any $M^{\left(\epsilon_{b}, \epsilon_{s}\right)} \in \mathcal{M}^{\left(\epsilon_{b}, \epsilon_{s}\right)}$, there exists a $\left(\hat{\epsilon}_{b}, \hat{\epsilon}_{s}\right) \ll\left(\epsilon_{b}, \epsilon_{s}\right)$ and a trading outcome $M^{\left(\hat{\epsilon}_{b}, \hat{\epsilon}_{s}\right)} \in \mathcal{M}^{\left(\hat{\epsilon}_{b}, \hat{\epsilon}_{s}\right)}$ such that the ex-ante probability of trade in the event that both players are strategic type is strictly higher in $M^{\left(\hat{\epsilon}_{b}, \hat{\epsilon}_{s}\right)}$ than in $M^{\left(\epsilon_{b}, \epsilon_{s}\right)}$. The next step is to prove that any equilibrium outcome of any $\Gamma^{\left(k, \epsilon_{b}, \epsilon_{s}\right)}$ in which the ex-ante probability of trade among the strategic types is at least as high $\frac{9}{32}$ is an element of the set of trading outcomes $\mathcal{M}^{\left(\epsilon_{b}, \epsilon_{s}\right)}$. The bid of the strategic-type player is weakly increasing in her valuation and therefore the equilibrium outcome satisfies the restriction mentioned above. Using the second step, we are then able to construct a sequence of trading outcomes each in $\mathcal{M}^{\left(\epsilon_{b}^{n}, \epsilon_{s}^{n}\right)}$ with $\left(\epsilon_{b}^{n}, \epsilon_{s}^{n}\right)$ converging to $(0,0)$ and the ex-ante probabilities of trade between the strategic types in the corresponding trading outcomes converging to some value greater than $\frac{9}{32}$. Then we construct a trading outcome for the bilateral trading problem in which both players are only 
strategic type and their valuations are distributed uniformly on $[0,1]$, which has a higher exante probability of trade than $\frac{9}{32}$. This contradicts the result of Myerson and Satterthwaite [15] mentioned above.

There is an intuitive way to understand why Proposition 3.1 is true. Although this intuition is different from the method of proof presented in this paper, we expect it can be used to prove the same result for at least differentiable and strictly increasing pair of equilibrium strategies. Starting from an equilibrium pair of strategies of $\Gamma^{\left(k, \epsilon_{b}, \epsilon_{s}\right)}$, any slight increase in $\epsilon_{s}$ increases the probability that the seller bids "lower" because the trustworthytype seller does not exaggerate her bid. This makes it "cheaper" for the strategic-type buyer to bid lower. Similarly, any slight increase in $\epsilon_{b}$ increases the probability that the buyer bids "higher", which in turn makes it "cheaper" for the strategic-type seller to bid higher. With the strategic-type buyer bidding lower and the strategic-type seller bidding higher, the probability of trade between them falls.

\subsection{Direct Mechanism}

The next proposition shows that if we are not restricted to the set of $k$-double auctions but allowed to choose any trading mechanism from the set of direct mechanisms, then we can always construct a new direct mechanism that has at least as high probability of trade among the strategic types as in the mechanism that was in use before the increase in the levels of trust.

Proposition 3.2. Suppose for the bilateral trading problem $\left.\left(\left(\epsilon_{b}, \epsilon_{s}\right),\left(F_{s t_{i}}, F_{t r_{i}}\right)_{i=b, s}\right)\right)$, where $\left(\epsilon_{b}, \epsilon_{s}\right) \ll(1,1)$, the direct mechanism $\left(p_{\left(d_{b}, d_{s}\right)}, x_{\left(d_{b}, d_{s}\right)}\right)_{d_{b}=s t, t r ; d_{s}=s t, t r}$ satisfies IC and IR. Consider any $\left(\epsilon_{b}^{\prime}, \epsilon_{s}^{\prime}\right)$ such that $\left(\epsilon_{b}, \epsilon_{s}\right) \leq\left(\epsilon_{b}^{\prime}, \epsilon_{s}^{\prime}\right) \ll(1,1)$. Then there exists a direct mechanism $\left(p_{\left(d_{b}, d_{s}\right)}^{\prime}, x_{\left(d_{b}, d_{s}\right)}^{\prime}\right) d_{b}=s t, t r ; d_{s}=s t, t r$ for the bilateral trading problem $\left.\left(\left(\epsilon_{b}^{\prime}, \epsilon_{s}^{\prime}\right),\left(F_{s t_{i}}, F_{t r_{i}}\right)_{i=b, s}\right)\right)$ 
satisfying $I C$ and $I R$, which is such that

$$
\int_{\left[\underline{a}_{b}, \bar{a}_{b}\right]} \int_{\left[\underline{a}_{s}, \bar{a}_{s}\right]} p_{(s t, s t)}^{\prime}\left(v_{b}, v_{s}\right) f_{s t_{s}} f_{s t_{b}} d v_{s} d v_{b} \geq \int_{\left[\underline{a}_{b}, \bar{a}_{b}\right]} \int_{\left[\underline{a}_{s}, \bar{a}_{s}\right]} p_{(s t, s t)}\left(v_{b}, v_{s}\right) f_{s t_{s}} f_{s t_{b}} d v_{s} d v_{b} .
$$

An increase in the levels of trust does not relax the $I C$ and $I R$ constraints. Instead, more weight is put on the outcome associated with a trustworthy opponent for each type of a player. In the proof, we construct a direct mechanism $\left(p_{\left(d_{b}, d_{s}\right)}^{\prime}, x_{\left(d_{b}, d_{s}\right)}^{\prime}\right)$ that reduces proportionately for each type of a player both the probability of trade and the payment whenever that player meets with a trustworthy opponent. This then reduces the payoff of each type of a player in a fixed proportion. Moreover, this proportion is kept constant across all valuation types of the strategic type of a player to ensure $I C^{*}$. However, to stop a strategic type from misreporting herself as trustworthy, the payoff of any valuation type of the trustworthy-type player is reduced by a greater proportion than the payoff of any valuation type of the strategic type of that player. The constructed mechanism satisfies $I R$ since the payoffs of the players in that mechanism are proportional to the payoffs in the older mechanism $\left(p_{\left(d_{b}, d_{s}\right)}, x_{\left(d_{b}, d_{s}\right)}\right)$. We do not use the sufficient conditions of Proposition 2.7 for this proof, so the constructed mechanism $\left(p_{\left(d_{b}, d_{s}\right)}^{\prime}, x_{\left(d_{b}, d_{s}\right)}^{\prime}\right)$ does not push the trustworthy types to 0 payoffs.

\subsection{Constraint-Inefficiency of $k$-Double Auctions}

Myerson and Satterthwaite [15] prove that the set of $k$-double auctions is constraint-efficient if the valuations of the players are distributed uniformly and independently on $[0,1]$ and $\epsilon_{b}=\epsilon_{s}=0$. This is because in this trading problem, the C-S equilibrium outcome of a

$\frac{1}{2}$-double auction attains the highest ex-ante probability of trade (equal to $\frac{9}{32}$ ) relative to any equilibrium outcome of any trading mechanism. We now argue that this result is not robust. 
Proposition 3.1 tells us that if the valuations of the players are distributed uniformly and independently on $[0,1]$ and $(0,0) \ll\left(\epsilon_{b}, \epsilon_{s}\right) \ll(1,1)$, then the ex-ante probability of trade among the strategic types in any equilibrium outcome of any $k$-double auction is strictly less than $\frac{9}{32}$. Since it is possible to attain an ex-ante probability of trade among the strategic types equal to $\frac{9}{32}$ when $\epsilon_{b}=\epsilon_{s}=0$, Proposition 3.2 tells us that for any $\left(\epsilon_{b}, \epsilon_{s}\right)$, there exist direct mechanisms with the ex-ante probability of trade among the strategic types at least as high as $\frac{9}{32}$. Hence, for generic $\left(\epsilon_{b}, \epsilon_{s}\right)$, the set of $k$-double auctions is constraint-inefficient in the trading problem with uniform priors on the set of valuations. In other words, constraintefficiency of the set of $k$-double auctions is not robust to perturbations in the disposition type of the players.

\section{Is Ex-Post Efficiency Possible?}

Proposition 3.2 tells us that as the levels of trust increase, we can weakly reduce the inefficiency caused by the strategic behavior if we are allowed to use direct mechanisms. What is the limit of this fall in inefficiency? Can we get ex-post efficiency?

An outcome of a mechanism is ex-post efficient for the strategic types if trade occurs if and only if the valuation type of the strategic buyer is at least as high as the valuation type of the strategic seller.

Definition 4.1. $E X^{*}$ : An outcome of a trading mechanism is ex-post efficient for the strategic types if

$$
p_{(s t, s t)}\left(v_{b}, v_{s}\right)= \begin{cases}1 & \text { if } v_{b} \geq v_{s} \\ 0 & \text { if } v_{b}<v_{s}\end{cases}
$$

We can similarly define ex-post efficiency. 
Definition 4.2. $E X$ : An outcome of a trading mechanism is ex-post efficient if $\forall\left(d_{b}, d_{s}\right)$,

$$
p_{\left(d_{b}, d_{s}\right)}\left(v_{b}, v_{s}\right)= \begin{cases}1 & \text { if } v_{b} \geq v_{s} \\ 0 & \text { if } v_{b}<v_{s}\end{cases}
$$

Note that $E X \Longrightarrow E X^{*}$.

The following theorem is a restatement of Myerson and Satterthwaite [15, Corollary 1] which proves that when both players are only strategic type and the intersection of the intervals of players' valuations has a non-empty interior, then it is impossible to achieve ex-post efficiency in any outcome of any trading mechanism that satisfies $I C^{*}$ and $I R .^{11}$

Theorem 4.3. If $\epsilon_{b}=\epsilon_{s}=0$ and $\left(\underline{a}_{b}, \bar{a}_{b}\right) \cap\left(\underline{a}_{s}, \bar{a}_{s}\right) \neq \emptyset$, then there does not exist an outcome of any trading mechanism that satisfies $E X, I C^{*}$ and $I R$.

Proof: See Myerson and Satterthwaite [15, Corollary 1].

Myerson and Satterthwaite [15] showed that any outcome of a trading mechanism that satisfies $E X$ and $I C^{*}$ will require an ex-ante subsidy of at least $\int_{\left[a_{b}, \bar{a}_{s}\right]}\left(1-F_{s t_{b}}(y)\right) F_{s t_{s}}(y) d y$ to satisfy $I R$ since the expected cost of $I C^{*}$ exceeds the expected gains from trade by that amount. Section 4.1 shows how this subsidy can be generated if and only if at least one player has a high enough trust in the other player. The constructed optimal trading mechanism is a direct mechanism. Section 4.2 , however, shows that $k$-double auctions with or without any form of pre-play communication are ex-post inefficient for all levels of trust.

\subsection{Achieving Ex-Post Efficiency Using Direct Mechanisms}

Proposition 4.4. There exist weakly decreasing functions $\psi_{i}:[0,1] \rightarrow[0,1], i=b, s$ with $\psi_{i}\left(\epsilon_{i}\right)<1 \forall \epsilon_{i}>0$, such that for all $\left(\hat{\epsilon}_{i}, \hat{\epsilon}_{j}\right) \geq\left(\epsilon_{i}, \psi_{i}\left(\epsilon_{i}\right)\right)$ there exist direct mechanisms that satisfy IC, IR and $E X$ (and hence, they also satisfy $E X^{*}$ ).

\footnotetext{
${ }^{11}$ Note that in this case, $E X^{*}$ is equivalent to $E X$ and $I C^{*}$ is equivalent to $I C$.
} 
We use Proposition 2.7 in the proof. The first three conditions in Proposition 2.7 are trivially satisfied by any $E X$ outcome. Moreover, (2) is satisfied if the probabilities of trustworthy types are high enough. When the probabilities of trustworthy types are high enough, the ex-ante gains from trade are greater than the expected cost of $I C^{*}$ in a direct mechanism that satisfies $E X$ because of the truthful revelation by the trustworthy types. Note that the payment functions constructed in the proof of Proposition 2.7 are such that every valuation type of the trustworthy-type player gets an expected-payoff of 0 . Thus, by pushing the trustworthy types to their individual rationality constraints, we extract all the ex-ante gains from trade that they generate and then redistribute them using lump-sum transfers to the strategic types. So, and this point is crucial, we use the gains of the trustworthy types to subsidize the strategic types in order to induce the latter to report truthfully. Hence, it becomes possible to get an ex-post efficient outcome even while satisfying $I C$ and $I R$.

Proposition 4.4 also brings forward the trade-off between the levels of trust of the two players: an increase in the level of trust of one player in the other player reduces the threshold on the level of trust of the latter player on the former player that is needed to achieve ex-post efficiency.

\subsection{Inefficiency of $k$-double auctions}

If any $\epsilon_{i}=1$, then it is straightforward to satisfy $E X$ in a $k$-double auction. For instance, if $\epsilon_{b}=1$, then take $k=1$. In this double auction, truthful bid dominates any other bid for the strategic-type seller. All trustworthy types of both the buyer and seller bid truthfully. So we get an ex-post efficient outcome. Therefore, in what follows, we assume $\left(\epsilon_{b}, \epsilon_{s}\right) \ll(1,1)$.

Proposition 4.5. If $\left(\epsilon_{b}, \epsilon_{s}\right) \ll(1,1)$ and $\left(\underline{a}_{s}, \bar{a}_{s}\right) \cap\left(\underline{a}_{b}, \bar{a}_{b}\right) \neq \Phi$, then no Bayesian-Nash equilibrium outcome of any $k$-double auction satisfies $E X^{*}$, and hence, it also does not satisfy EX. 
The above inefficiency result applies to $k$-double auctions in which players do not communicate before submitting their bids. Players can "reduce" the uncertainty by communicating their types in equilibrium (Farrell and Gibbons [5]). Since incomplete information is the reason for inefficiency, we could ask whether allowing for pre-play communication generates ex-post efficient outcomes. To answer this question, let's consider a $k$-double auction with a pre-play communication stage, in which players communicate, sequentially or simultaneously, using some arbitrary message space before the final stage during which they play according to the rules of the $k$-double auction. In this case, assuming that the trustworthy types bid truthfully in the $k$-double auction stage of the game seems to be a strong restriction on their behavior. For example, the trustworthy types may make pre-play nonbinding verbal agreements to bid some value not equal to their valuation and then fulfilling such agreements in the bidding stage. So we instead make the weakest possible assumption about the bidding behavior of the trustworthy types. We assume that the trustworthy types do not bid "irrationally", that is, the trustworthy buyer (seller) does not bid greater (less) than her valuation. This assumption does not restrict the behavior of the trustworthy types in the communication stage apart from not allowing such types to verbally agree to bid "irrationally".

Assumption 4.6. In a $k$-double auction with pre-play communication, the trustworthy buyer does not bid more than her valuation and the trustworthy seller does not bid less than her valuation.

Proposition 4.7. Suppose Assumption 4.6 holds. If $\underline{a}_{b} \leq \underline{a}_{s}$ and $\bar{a}_{b} \leq \bar{a}_{s}$, then for all $\left(\epsilon_{b}, \epsilon_{s}\right) \ll(1,1)$, no Bayesian-Nash equilibrium outcome of any $k$-double auction with preplay communication satisfies $E X$.

Intuitively, the reason for inefficiency is that a $k$-double auction with or without pre-play communication is unable to adequately subsidize the strategic types to ensure that they do 
not misreport their respective types. Since trade occurs at a weighted average of the two bids and the trustworthy-type buyer bids at most her valuation and the trustworthy-type seller bids at least her valuation, the trustworthy types are able to retain enough gains from trade for themselves. In a direct mechanism, these gains from trade could be transferred to the strategic types to satisfy their incentive constraints but this cannot be done in $k$-double auctions because of the weighted-average pricing rule.

Remark 4.8. Two remarks need to be made regarding Proposition 4.7.

1. We have proved that any equilibrium outcome of any $k$-double auction with preplay communication will not satisfy $E X$, which does not imply that any equilibrium outcome will not satisfy $E X^{*}$. However, it seems reasonable that the behavior of trustworthy types in a $k$-double auction with pre-play communication is such that if a pair of valuation types of the strategic-type players for whom the gains from trade are non-negative, trade in equilibrium with probability 1, then the same pair of valuation types must also trade in equilibrium with probability 1 if one or both the players are trustworthy type. More precisely, trustworthy behavior should imply that the following holds in any equilibrium outcome of any $k$-double auction with pre-play communication: if for any $\left(v_{b}, v_{s}\right)$, with $v_{b} \geq v_{s}, p_{(s t, s t)}\left(v_{b}, v_{s}\right)=1$, then $p_{(t r, s t)}\left(v_{b}, v_{s}\right)=p_{(s t, t r)}\left(v_{b}, v_{s}\right)=p_{(t r, t r)}\left(v_{b}, v_{s}\right)=1$. If the equilibrium outcome satisfies this property, then $E X^{*}$ is equivalent to $E X$ and hence, Proposition 4.7 will imply that no equilibrium of any $k$-double auction with pre-play communication will satisfy $E X^{*}$.

2. The proposition is valid if $\underline{a}_{b} \leq \underline{a}_{s}$ and $\bar{a}_{b} \leq \bar{a}_{s}$. In particular, it is true when the interval of valuations coincide. However, we have not been successful in proving the proposition if either $\underline{a}_{s}<\underline{a}_{b}$ or $\bar{a}_{s}<\bar{a}_{b}$. 


\section{Conclusion}

We introduced trustworthy-type traders in bilateral trading and studied the consequence of the resulting uncertainty regarding each others trustworthiness on the behavior of the strategic-type traders. We showed that an increase in the levels of trust can reduce the maximum probability of trade among the strategic types that is attainable using any trading mechanism from the set of $k$-double auctions. This is because the strategic-type traders try to capitalize on the trustworthy-type traders' honesty. We also argued that this negative result reflects a lack of flexibility of design in the set of $k$-double auctions compared to the set of direct mechanisms since it is always possible to construct direct mechanisms that have weakly higher probability of trade among the strategic types whenever there is an increase in the levels of trust. As a consequence, $k$-double auctions were shown to be generically (w.r.t. the levels of trust) constraint-inefficient in the trading problem with uniform priors.

A positive result of this study, in contrast to the previously known Impossibility Theorem (Myerson and Satterthwaite [15]), is that if at least one player has a high enough level of trust in the other player, then for any bilateral trading problem, it is possible to construct incentive compatible and individually rational direct mechanisms that are ex-post efficient. These efficient mechanisms induce the strategic types to reveal truthfully by providing them enough subsidy through lump-sum transfers of the gains of the trustworthy types. This subsidization, however, is not adequate in the set of $k$-double auctions and therefore, $k$ double auctions are inefficient for all levels of trust. In fact, for the same reason, any form of communication between the players before they use a $k$-double auction to trade will not help in achieving ex-post efficiency.

The notably different effect of trust in the set of direct mechanisms vis-à-vis the set of $k$ -

double auctions caution against generalizations regarding the consequence of trust in various institutions. The structure and rules of different institutions imply different opportunities 
for and consequences of strategic behavior. The rules of $k$-double auctions are such that the strategic types act "tough" if they believe that the other player could be trustworthy; whereas the same belief can be used in direct mechanisms to give incentives to the strategic types to reveal truthfully. This also emphasizes that by designing the "right" institutions, we can provide incentives to the strategic types that improve the welfare of society.

\section{Proofs}

We only provide proofs for one player to avoid repetition. $t_{i}$ is the bid of player $i, \sigma_{i}\left(v_{i}\right)$ is the equilibrium strategy (mixed or pure) of the strategic-type of player $i$ with valuation type $v_{i}, \operatorname{Supp}\left(\sigma_{i}\left(v_{i}\right)\right)$ is the support of $\sigma_{i}\left(v_{i}\right)$ and $G_{i}$ is the distribution of bids induced by $\sigma_{i}$. Let $\underline{t}_{i}=\sup \left\{t_{i} \mid G_{i}\left(t_{i}\right)=0\right\}$ and $\bar{t}_{i}=\inf \left\{t_{i} \mid G_{i}\left(t_{i}\right)=1\right\}$.

Proof of Lemma 2.5: $I C^{*}$ implies that $\forall v_{b}, v_{b}^{\prime}$

$$
U_{(b, s t)}\left(v_{b}\right)=v_{b} \bar{p}_{(b, s t)}\left(v_{b}\right)-\bar{x}_{(b, s t)}\left(v_{b}\right) \geq v_{b} \bar{p}_{(b, s t)}\left(v_{b}^{\prime}\right)-\bar{x}_{(b, s t)}\left(v_{b}^{\prime}\right)
$$

and

$$
U_{(b, s t)}\left(v_{b}^{\prime}\right)=v_{b}^{\prime} \bar{p}_{(b, s t)}\left(v_{b}^{\prime}\right)-\bar{x}_{(b, s t)}\left(v_{b}^{\prime}\right) \geq v_{b}^{\prime} \bar{p}_{(b, s t)}\left(v_{b}\right)-\bar{x}_{(b, s t)}\left(v_{b}\right) .
$$

Therefore we must have,

$$
\left(v_{b}-v_{b}^{\prime}\right) \bar{p}_{(b, s t)}\left(v_{b}\right) \geq U_{(b, s t)}\left(v_{b}\right)-U_{(b, s t)}\left(v_{b}^{\prime}\right) \geq\left(v_{b}-v_{b}^{\prime}\right) \bar{p}_{(b, s t)}\left(v_{b}^{\prime}\right) .
$$

Hence if $v_{b}>v_{b}^{\prime}$ then it must be that $\bar{p}_{(b, s t)}\left(v_{b}\right) \geq \bar{p}_{(b, s t)}\left(v_{b}^{\prime}\right)$. This then implies that 
$\frac{d U_{(b, s t)}}{d v_{b}}=\bar{p}_{(b, s t)}\left(v_{b}\right)$ at almost all $v_{b}$. Therefore we get

$$
U_{(b, s t)}\left(v_{b}\right)=U_{(b, s t)}\left(\underline{a}_{b}\right)+\int_{\left[\underline{a}_{b}, v_{b}\right]} \bar{p}_{(b, s t)}\left(y_{b}\right) d y_{b} .
$$

Similarly we can show that if $v_{s}>v_{s}^{\prime}$ then it must be that $\bar{p}_{(s, s t)}\left(v_{s}\right) \leq \bar{p}_{(s, s t)}\left(v_{s}^{\prime}\right)$ and $U_{(s, s t)}\left(v_{s}\right)=U_{(s, s t)}\left(\bar{a}_{s}\right)+\int_{\left[v_{s}, \bar{a}_{s}\right]} \bar{p}_{(s, s t)}\left(y_{s}\right) d y_{s}$.

Any mechanism that satisfies $I C^{*}$ must be such that

$$
\begin{aligned}
& \left(1-\epsilon_{b}\right)\left(1-\epsilon_{s}\right) \int_{\left[\underline{a}_{b}, \bar{a}_{b}\right]} \int_{\left[\underline{a}_{s}, \bar{a}_{s}\right]}\left(v_{b}-v_{s}\right) p_{(s t, s t)}\left(v_{b}, v_{s}\right) f_{s t_{s}} f_{s t_{b}} d v_{s} d v_{b} \\
& +\epsilon_{b}\left(1-\epsilon_{s}\right) \int_{\left[\underline{a}_{b}, \bar{a}_{b}\right]} \int_{\left[\underline{a}_{s}, \bar{a}_{s}\right]}\left(v_{b}-v_{s}\right) p_{(t r, s t)}\left(v_{b}, v_{s}\right) f_{s t_{s}} f_{t r_{b}} d v_{s} d v_{b} \\
& +\epsilon_{s}\left(1-\epsilon_{b}\right) \int_{\left[\underline{a}_{b}, \bar{a}_{b}\right]} \int_{\left[\underline{a}_{s}, \bar{a}_{s}\right]}\left(v_{b}-v_{s}\right) p_{(s t, t r)}\left(v_{b}, v_{s}\right) f_{t r_{s}} f_{s t_{s}} d v_{s} d v_{b} \\
& +\epsilon_{b} \epsilon_{s} \int_{\left[\underline{a}_{b}, \bar{a}_{b}\right]} \int_{\left[\underline{a}_{s}, \bar{a}_{s}\right]}\left(v_{b}-v_{s}\right) p_{(t r, t r)}\left(v_{b}, v_{s}\right) f_{t r_{s}} f_{t r_{b}} d v_{s} d v_{b} \\
& =\left(1-\epsilon_{b}\right) \int_{\left[\underline{a}_{b}, \bar{a}_{b}\right]} U_{(b, s t)}\left(v_{b}\right) f_{s t_{b}} d v_{b}+\epsilon_{b} \int_{\left[\underline{a}_{b}, \bar{a}_{b}\right]} U_{(b, t r)}\left(v_{b}\right) f_{t r_{b}} d v_{b} \\
& +\left(1-\epsilon_{s}\right) \int_{\left[\underline{a}_{s}, \bar{a}_{s}\right]} U_{(s, s t)}\left(v_{s}\right) f_{s t_{s}} d v_{s}+\epsilon_{s} \int_{\left[\underline{a}_{s}, \bar{a}_{s}\right]} U_{(s, t r)}\left(v_{s}\right) f_{t r_{s}} d v_{s} \\
& =\left(1-\epsilon_{b}\right)\left(U_{(b, s t)}\left(\underline{a}_{b}\right)+\int_{\left[\underline{a}_{b}, \bar{a}_{b}\right]} \int_{\left[\underline{a}_{b}, v_{b}\right]} \bar{p}_{(b, s t)}\left(y_{b}\right) d y_{b} f_{s t_{b}} d v_{b}\right) \\
& +\left(1-\epsilon_{s}\right)\left(U_{(s, s t)}\left(\bar{a}_{s}\right)+\int_{\left[\underline{a}_{s}, \bar{a}_{s}\right]} \int_{\left[v_{s}, \bar{a}_{s}\right]} \bar{p}_{(s, s t)}\left(y_{s}\right) d y_{s} f_{s t_{s}} d v_{s}\right) \\
& +\epsilon_{b} \int_{\left[\underline{a}_{b}, \bar{a}_{b}\right]} U_{(b, t r)}\left(v_{b}\right) f_{t r_{b}} d v_{b}+\epsilon_{s} \int_{\left[\underline{a}_{s}, \bar{a}_{s}\right]} U_{(s, t r)}\left(v_{s}\right) f_{t r_{s}} d v_{s} \\
& =\left(1-\epsilon_{b}\right) U_{(b, s t)}\left(\underline{a}_{b}\right)+\left(1-\epsilon_{s}\right) U_{(s, s t)}\left(\bar{a}_{s}\right) \\
& +\epsilon_{b} \int_{\left[\underline{a}_{b}, \bar{a}_{b}\right]} U_{(b, t r)}\left(v_{b}\right) f_{t r_{b}} d v_{b}+\epsilon_{s} \int_{\left[\underline{a}_{s}, \bar{a}_{s}\right]} U_{(s, t r)}\left(v_{s}\right) f_{t r_{s}} d v_{s} \\
& +\left(1-\epsilon_{b}\right) \int_{\left[\underline{a}_{b}, \bar{a}_{b}\right]} \bar{p}_{(b, s t)}\left(v_{b}\right)\left(1-F_{s t_{b}}\left(v_{b}\right)\right) d v_{b}+\left(1-\epsilon_{s}\right) \int_{\left[\underline{a}_{s}, \bar{a}_{s}\right]} \bar{p}_{(s, s t)}\left(v_{s}\right) F_{s t_{s}}\left(v_{s}\right) d v_{s}
\end{aligned}
$$


However,

$$
\begin{aligned}
& \left(1-\epsilon_{b}\right) \int_{\left[\underline{a}_{b}, \bar{a}_{b}\right]} \bar{p}_{(b, s t)}\left(v_{b}\right)\left(1-F_{s t_{b}}\left(v_{b}\right)\right) d v_{b}+\left(1-\epsilon_{s}\right) \int_{\left[\underline{a}_{s}, \bar{a}_{s}\right]} \bar{p}_{(s, s t)}\left(v_{s}\right) F_{s t_{s}}\left(v_{s}\right) d v_{s} \\
& =\left(1-\epsilon_{b}\right)\left(1-\epsilon_{s}\right) \int_{\left[\underline{a}_{b}, \bar{a}_{b}\right]} \int_{\left[\underline{a}_{s}, \bar{a}_{s}\right]} p_{(s t, s t)}\left(v_{b}, v_{s}\right)\left(1-F_{s t_{b}}\left(v_{b}\right)\right) f_{s t_{s}} d v_{s} d v_{b} \\
& +\left(1-\epsilon_{b}\right) \epsilon_{s} \int_{\left[\underline{a}_{b}, \bar{a}_{b}\right]} \int_{\left[\underline{a}_{s}, \bar{a}_{s}\right]} p_{(s t, t r)}\left(v_{b}, v_{s}\right)\left(1-F_{s t_{b}}\left(v_{b}\right)\right) f_{t r_{s}} d v_{s} d v_{b} \\
& +\left(1-\epsilon_{s}\right)\left(1-\epsilon_{b}\right) \int_{\left[\underline{a}_{b}, \bar{a}_{b}\right]} \int_{\left[\underline{a}_{s}, \bar{a}_{s}\right]} p_{(s t, s t)}\left(v_{b}, v_{s}\right) F_{s t_{s}}\left(v_{s}\right) f_{s t_{b}} d v_{s} d v_{b} \\
& +\left(1-\epsilon_{s}\right) \epsilon_{b} \int_{\left[\underline{a}_{b}, \bar{a}_{b}\right]} \int_{\left[\underline{a}_{s}, \bar{a}_{s}\right]} p_{(t r, s t)}\left(v_{b}, v_{s}\right) F_{s t_{s}}\left(v_{s}\right) f_{t r_{b}} d v_{s} d v_{b}
\end{aligned}
$$

By subtracting the above equation from (3) we get (1).

Proof of Lemma 2.6: Since $\left(p_{\left(d_{b}, d_{s}\right)}, x_{\left(d_{b}, d_{s}\right)}\right)$ satisfies $I C$ and $I R$,

$$
\begin{aligned}
U_{(b, s t)}\left(v_{b}\right) & =U_{(b, s t)}\left(\underline{a}_{b}\right)+\int_{\left[\underline{a}_{b}, v_{b}\right]} \bar{p}_{(b, s t)}\left(y_{b}\right) d y_{b} \\
& \geq v_{b} \bar{p}_{(b, t r)}\left(v_{b}^{\prime}\right)-\bar{x}_{(b, t r)}\left(v_{b}^{\prime}\right) \\
& \geq v_{b} \bar{p}_{(b, t r)}\left(v_{b}^{\prime}\right)-v_{b}^{\prime} \bar{p}_{(b, t r)}\left(v_{b}^{\prime}\right) \\
& =\left(v_{b}-v_{b}^{\prime}\right) \bar{p}_{(b, t r)}\left(v_{b}^{\prime}\right),
\end{aligned}
$$

where the second inequality follows from $I R$ for trustworthy types.

Proof of Proposition 2.7: Consider the following cases: 
Case 1: $\epsilon_{b}<1$ and $\epsilon_{s}<1$. Define

$$
\begin{aligned}
x_{(s t, s t)}\left(v_{b}, v_{s}\right)= & \frac{1}{1-\epsilon_{s}} \int_{\left[\underline{a}_{b}, v_{b}\right]} y_{b} d \bar{p}_{(b, s t)}\left(y_{b}\right)+\frac{1}{1-\epsilon_{b}} \int_{\left[\underline{a}_{s}, v_{s}\right]} y_{s} d \bar{p}_{(s, s t)}\left(y_{s}\right) \\
& +\frac{1}{1-\epsilon_{s}} \underline{a}_{b} \bar{p}_{b}\left(\underline{a}_{b}\right)-\frac{1}{1-\epsilon_{b}} \int_{\left[\underline{a}_{s}, \bar{a}_{s}\right]} y_{s}\left(1-F_{s t_{s}}\left(y_{s}\right)\right) d \bar{p}_{(s, s t)}\left(y_{s}\right) \\
& -\frac{\epsilon_{s}}{\left(1-\epsilon_{b}\right)\left(1-\epsilon_{s}\right)} \int_{\left[\underline{a}_{s}, \bar{a}_{s}\right]} y_{s} \bar{p}_{(s, t r)}\left(y_{s}\right) f_{t r_{s}}\left(y_{s}\right) d y_{s} \\
x_{(s t, t r)}\left(v_{b}, v_{s}\right)= & \frac{1}{1-\epsilon_{b}} v_{s} \bar{p}_{(s, t r)}\left(v_{s}\right) \\
x_{(t r, s t)}\left(v_{b}, v_{s}\right)= & \frac{1}{1-\epsilon_{s}} v_{b} \bar{p}_{(b, t r)}\left(v_{b}\right) \\
x_{(t r, t r)}\left(v_{b}, v_{s}\right)= & 0
\end{aligned}
$$

It is easy to calculate that:

$$
\begin{aligned}
\bar{x}_{(b, s t)}\left(v_{b}\right)= & \int_{\left[\underline{a}_{b}, v_{b}\right]} y_{b} d \bar{p}_{(b, s t)}\left(y_{b}\right)+\frac{1-\epsilon_{s}}{1-\epsilon_{b}} \int_{\left[\underline{a}_{s}, \bar{a}_{s}\right]} \int_{\left[\underline{a}_{s}, v_{s}\right]} y_{s} f_{s t_{s}}\left(v_{s}\right) d \bar{p}_{(s, s t)}\left(y_{s}\right) d v_{s} \\
& +\underline{a}_{b} \bar{p}_{b}\left(\underline{a}_{b}\right)-\frac{1-\epsilon_{s}}{1-\epsilon_{b}} \int_{\left[\underline{a}_{s}, \bar{a}_{s}\right]} y_{s}\left(1-F_{s t_{s}}\left(y_{s}\right)\right) d \bar{p}_{(s, s t)}\left(y_{s}\right) \\
& -\frac{\epsilon_{s}}{1-\epsilon_{b}} \int_{\left[\underline{a}_{s}, \bar{a}_{s}\right]} y_{s} \bar{p}_{(s, t r)}\left(y_{s}\right) f_{t r_{s}}\left(y_{s}\right) d y_{s}+\frac{\epsilon_{s}}{1-\epsilon_{b}} \int_{\left[\underline{a}_{s}, \bar{a}_{s}\right]} v_{s} \bar{p}_{(s, t r)}\left(v_{s}\right) f_{t r_{s}}\left(v_{s}\right) d v_{s} \\
= & \int_{\left[\underline{a}_{b}, v_{b}\right]} y_{b} d \bar{p}_{(b, s t)}\left(y_{b}\right)+\frac{1-\epsilon_{s}}{1-\epsilon_{b}} \int_{\left[\underline{a}_{s}, \bar{a}_{s}\right]} y_{s}\left(1-F_{s t_{s}}\left(y_{s}\right)\right) d \bar{p}_{(s, s t)}\left(y_{s}\right) \\
& +\underline{a}_{b} \bar{p}_{b}\left(\underline{a}_{b}\right)-\frac{1-\epsilon_{s}}{1-\epsilon_{b}} \int_{\left[\underline{a}_{s}, \bar{a}_{s}\right]} y_{s}\left(1-F_{s t_{s}}\left(y_{s}\right)\right) d \bar{p}_{(s, s t)}\left(y_{s}\right) \\
= & \int_{\left[\underline{a}_{b}, v_{b}\right]} y_{b} d \bar{p}_{(b, s t)}\left(y_{b}\right)+\underline{a}_{b} \bar{p}_{b}\left(\underline{a}_{b}\right)
\end{aligned}
$$




$$
\begin{aligned}
\bar{x}_{(s, s t)}\left(v_{s}\right)= & \frac{1-\epsilon_{b}}{1-\epsilon_{s}} \int_{\left[\underline{a}_{b}, \bar{a}_{b}\right]} \int_{\left[\underline{a}_{b}, v_{b}\right]} y_{b} f_{s t_{b}}\left(v_{b}\right) d \bar{p}_{(b, s t)}\left(y_{b}\right) d v_{b}+\int_{\left[\underline{a}_{s}, v_{s}\right]} y_{s} d \bar{p}_{(s, s t)}\left(y_{s}\right) \\
& +\frac{1-\epsilon_{b}}{1-\epsilon_{s}} \underline{a}_{b} \bar{p}_{b}\left(\underline{a}_{b}\right)-\int_{\left[\underline{a}_{s}, \bar{a}_{s}\right]} y_{s}\left(1-F_{s t_{s}}\left(y_{s}\right)\right) d \bar{p}_{(s, s t)}\left(y_{s}\right) \\
& -\frac{\epsilon_{s}}{1-\epsilon_{s}} \int_{\left[\underline{a}_{s}, \bar{a}_{s}\right]} y_{s} \bar{p}_{(s, t r)}\left(y_{s}\right) f_{t r_{s}}\left(y_{s}\right) d y_{s}+\frac{\epsilon_{b}}{1-\epsilon_{s}} \int_{\left[\underline{a}_{b}, \bar{a}_{b}\right]} v_{b} \bar{p}_{(b, t r)}\left(v_{b}\right) f_{t r_{b}}\left(v_{b}\right) d v_{b} \\
\bar{x}_{(b, t r)}\left(v_{b}\right)= & v_{b} \bar{p}_{(b, t r)}\left(v_{b}\right) \\
\bar{x}_{(s, t r)}\left(v_{s}\right)= & v_{s} \bar{p}_{(s, t r)}\left(v_{s}\right)
\end{aligned}
$$

Then the payoffs of the strategic types are:

$$
\begin{aligned}
U_{(b, s t)}\left(v_{b}\right)= & v_{b} \bar{p}_{(b, s t)}\left(v_{b}\right)-\int_{\left[\underline{a}_{b}, v_{b}\right]} y_{b} d \bar{p}_{(b, s t)}\left(y_{b}\right)-\underline{a}_{b} \bar{p}_{b}\left(\underline{a}_{b}\right) \\
U_{(s, s t)}\left(v_{s}\right)= & -v_{s} \bar{p}_{(s, s t)}\left(v_{s}\right)+\frac{1-\epsilon_{b}}{1-\epsilon_{s}} \int_{\left[\underline{a}_{b}, \bar{a}_{b}\right]} \int_{\left[\underline{a}_{b}, v_{b}\right]} y_{b} f_{s t_{b}}\left(v_{b}\right) d \bar{p}_{(b, s t)}\left(y_{b}\right) d v_{b}+\int_{\left[\underline{a}_{s}, v_{s}\right]} y_{s} d \bar{p}_{(s, s t)}\left(y_{s}\right) \\
& +\frac{1-\epsilon_{b}}{1-\epsilon_{s}} \underline{a}_{b} \bar{p}_{b}\left(\underline{a}_{b}\right)-\int_{\left[\underline{a}_{s}, \bar{a}_{s}\right]} y_{s}\left(1-F_{s t_{s}}\left(y_{s}\right)\right) d \bar{p}_{(s, s t)}\left(y_{s}\right) \\
& -\frac{\epsilon_{s}}{1-\epsilon_{s}} \int_{\left[\underline{a}_{s}, \bar{a}_{s}\right]} y_{s} \bar{p}_{(s, t r)}\left(y_{s}\right) f_{t r_{s}}\left(y_{s}\right) d y_{s}+\frac{\epsilon_{b}}{1-\epsilon_{s}} \int_{\left[\underline{a}_{b}, \bar{a}_{b}\right]} v_{b} \bar{p}_{(b, t r)}\left(v_{b}\right) f_{t r_{b}}\left(v_{b}\right) d v_{b}
\end{aligned}
$$

The trustworthy types satisfy their $I R$ constraints because

$$
\begin{gathered}
U_{(b, t r)}\left(v_{b}\right)=v_{b} \bar{p}_{(b, t r)}\left(v_{b}\right)-\bar{x}_{(b, t r)}\left(v_{b}\right)=v_{b} \bar{p}_{(b, t r)}\left(v_{b}\right)-v_{b} \bar{p}_{(b, t r)}\left(v_{b}\right)=0 \\
U_{(s, t r)}\left(v_{s}\right)=\bar{x}_{(s, t r)}\left(v_{s}\right)-v_{s} \bar{p}_{(s, t r)}\left(v_{s}\right)=v_{s} \bar{p}_{(s, t r)}\left(v_{s}\right)-v_{s} \bar{p}_{(s, t r)}\left(v_{s}\right)=0 .
\end{gathered}
$$


Next we check $I C^{*} . \forall v_{b}^{\prime}<v_{b}$, we have (a similar argument works if $v_{b}^{\prime}>v_{b}$ )

$$
\begin{aligned}
& v_{b} \bar{p}_{(b, s t)}\left(v_{b}\right)-\bar{x}_{(b, s t)}\left(v_{b}\right)-\left(v_{b} \bar{p}_{(b, s t)}\left(v_{b}^{\prime}\right)-\bar{x}_{(b, s t)}\left(v_{b}^{\prime}\right)\right) \\
& =v_{b}\left(\bar{p}_{(b, s t)}\left(v_{b}\right)-\bar{p}_{(b, s t)}\left(v_{b}^{\prime}\right)\right)-\int_{\left[v_{b}^{\prime}, v_{b}\right]} y_{b} d \bar{p}_{(b, s t)}\left(y_{b}\right) \\
& =\int_{\left[v_{b}^{\prime}, v_{b}\right]}\left(v_{b}-y_{b}\right) d \bar{p}_{(b, s t)}\left(y_{b}\right) \geq 0
\end{aligned}
$$

$\forall v_{s}^{\prime}>v_{s}$, we have (a similar argument works if $v_{s}^{\prime}<v_{s}$ )

$$
\begin{aligned}
& \bar{x}_{(s, s t)}\left(v_{s}\right)-v_{s} \bar{p}_{(s, s t)}\left(v_{s}\right)-\left(\bar{x}_{(s, s t)}\left(v_{s}^{\prime}\right)-v_{s} \bar{p}_{(s, s t)}\left(v_{s}^{\prime}\right)\right) \\
& =\int_{\left[\underline{a}_{s}, v_{s}\right]} y_{s} d \bar{p}_{(s, s t)}\left(y_{s}\right)-v_{s} \bar{p}_{(s, s t)}\left(v_{s}\right)-\int_{\left[\underline{a}_{s}, v_{s}^{\prime}\right]} y_{s} d \bar{p}_{(s, s t)}\left(y_{s}\right)+v_{s} \bar{p}_{(s, s t)}\left(v_{s}^{\prime}\right) \\
& =v_{s}\left(\bar{p}_{(s, s t)}\left(v_{s}^{\prime}\right)-\bar{p}_{(s, s t)}\left(v_{s}\right)\right)-\int_{\left[v_{s}, v_{s}^{\prime}\right]} y_{s} d \bar{p}_{(s, s t)}\left(y_{s}\right) \\
& =\int_{\left[v_{s}, v_{s}^{\prime}\right]}\left(v_{s}-y_{s}\right) d \bar{p}_{(s, s t)}\left(y_{s}\right) \geq 0
\end{aligned}
$$

Therefore, the constructed mechanism satisfies $(1)$. Since $U_{(b, s t)}\left(\underline{a}_{b}\right)=0, U_{(b, t r)}\left(v_{b}\right)=$ $0 \forall v_{b}, U_{(s, t r)}\left(v_{s}\right)=0 \forall v_{s}$ and the functions $p_{(s t, s t)}, p_{(s t, t r)}, p_{(t r, s t)}, p_{(t r, t r)}$ satisfy (2), it implies that $U_{(s, t r)}\left(\bar{a}_{s}\right) \geq 0$. It is easy to see that $U_{(b, s t)}\left(v_{b}\right)$ is non-decreasing and $U_{(s, s t)}\left(v_{s}\right)$ is non-increasing, therefore, the mechanism satisfies $I R$ for the strategic types.

Now, we check that no strategic type will misreport herself as trustworthy type. Since the mechanism satisfies $I C^{*}$ and $U_{(b, s t)}\left(\underline{a}_{b}\right)=0$,

$$
\begin{aligned}
U_{(b, s t)}\left(v_{b}\right) & =U_{(b, s t)}\left(\underline{a}_{b}\right)+\int_{\left[\underline{a}_{b}, v_{b}\right]} \bar{p}_{(b, s t)}\left(y_{b}\right) d y_{b} \\
& =\int_{\left[\underline{a}_{b}, v_{b}\right]} \bar{p}_{(b, s t)}\left(y_{b}\right) d y_{b} \\
& \geq\left(v_{b}-v_{b}^{\prime}\right) \bar{p}_{(b, t r)}\left(v_{b}^{\prime}\right) \\
& =v_{b} \bar{p}_{(b, t r)}\left(v_{b}^{\prime}\right)-\bar{x}_{(b, t r)}\left(v_{b}^{\prime}\right)
\end{aligned}
$$


where the inequality follows from the second condition in the proposition. Similarly,

$$
\begin{aligned}
U_{(s, s t)}\left(v_{s}\right) & =U_{(s, s t)}\left(\bar{a}_{s}\right)+\int_{\left[v_{s}, \bar{a}_{s}\right]} \bar{p}_{(s, s t)}\left(y_{s}\right) d y_{s} \\
& \geq \int_{\left[v_{s}, \bar{a}_{s}\right]} \bar{p}_{(s, s t)}\left(y_{s}\right) d y_{s} \\
& \geq\left(v_{s}^{\prime}-v_{s}\right) \bar{p}_{(s, t r)}\left(v_{s}^{\prime}\right) \\
& =\bar{x}_{(s, t r)}\left(v_{s}^{\prime}\right)-v_{s} \bar{p}_{(s, t r)}\left(v_{s}^{\prime}\right)
\end{aligned}
$$

where the second inequality follows from the third condition in the proposition.

Case 2: $\epsilon_{b}=1$ and $\epsilon_{s}<1$. Define

$$
\begin{aligned}
x_{(t r, s t)}\left(v_{b}, v_{s}\right)= & \int_{\left[\underline{a}_{s}, v_{s}\right]} y_{s} d \bar{p}_{(s, s t)}\left(y_{s}\right)-\int_{\left[\underline{a}_{s}, \bar{a}_{s}\right]} y_{s}\left(1-F_{s t_{s}}\left(y_{s}\right)\right) d \bar{p}_{(s, s t)}\left(y_{s}\right) \\
& -\frac{\epsilon_{s}}{1-\epsilon_{s}} \int_{\left[\underline{a}_{s}, \bar{a}_{s}\right]} y_{s} \bar{p}_{(s, t r)}\left(y_{s}\right) f_{t r_{s}}\left(y_{s}\right) d y_{s}+\frac{1}{1-\epsilon_{s}} v_{b} \bar{p}_{(b, t r)}\left(v_{b}\right) \\
x_{(t r, t r)}\left(v_{b}, v_{s}\right)= & v_{s} \bar{p}_{(s, t r)}\left(v_{s}\right)
\end{aligned}
$$

It is straightforward to go through similar steps as we did for Case 1.

Case 3: $\epsilon_{b}<1$ and $\epsilon_{s}=1$. Define

$$
\begin{aligned}
x_{(s t, t r)}\left(v_{b}, v_{s}\right)= & \int_{\left[\underline{a}_{b}, v_{b}\right]} y_{b} d \bar{p}_{(b, s t)}\left(y_{b}\right)-\int_{\left[\underline{a}_{b}, \bar{a}_{b}\right]} y_{b}\left(1-F_{s t_{b}}\left(y_{b}\right)\right) d \bar{p}_{(b, s t)}\left(y_{b}\right) \\
& -\frac{\epsilon_{b}}{1-\epsilon_{b}} \int_{\left[\underline{a}_{b}, \bar{a}_{b}\right]} y_{b} \bar{p}_{(b, t r)}\left(y_{b}\right) f_{t r_{b}}\left(y_{b}\right) d y_{b}+\frac{1}{1-\epsilon_{b}} v_{s} \bar{p}_{(s, t r)}\left(v_{s}\right) \\
x_{(t r, t r)}\left(v_{b}, v_{s}\right)= & v_{b} \bar{p}_{(b, t r)}\left(v_{b}\right)
\end{aligned}
$$

Again, it is straightforward to go through similar steps as we did for Case 1. 
Case $4: \epsilon_{b}=\epsilon_{s}=1$. This case is trivial.

Proof of Proposition 3.1: Without loss of generality, assume that the bids of the players lie in $[0,1]$.

Case 1: $k=0$ or 1 . Suppose $k=0$. For all $\epsilon_{s}>0$, the strategic-type buyer strictly prefers to bid her valuation $v_{b}$ than any other bid in $\Gamma^{\left(k, \epsilon_{b}, \epsilon_{s}\right)}$. If she bids $t_{b}>v_{b}$, then she trades with all valuation types of the seller who bid in the interval $\left(v_{b}, t_{b}\right)$ and ends up paying a price greater than her valuation on those trades. Since the trustworthy types bid equal to their valuation, there exists a positive measure of such trades. The strategic-type buyer is therefore better off bidding equal to her valuation since this bid only reduces the probability of trades on which she gets a negative payoff. If she bids $t_{b}<v_{b}$, then she does not trade with all valuation types of the seller who bid in the interval $\left(t_{b}, v_{b}\right)$ (which is also a set of positive measure) whereas by bidding equal to her valuation she would have traded with these valuation types of the trustworthy-type seller without changing the price on any other trade.

So, from the point of view of the strategic-type seller, the buyer's bid is uniformly distributed on $[0,1]$ since both disposition types of the buyer bid equal to their respective valuations. Then, it is straightforward to see that the strategic-type seller will bid $\frac{1}{2}\left(1+v_{s}\right)$. Therefore, the ex-ante probability of trade in the event that both players are strategic type is $\frac{1}{4}<\frac{9}{32}$. A similar proof works if $k=1$.

Case 2: $k \in(0,1)$. We need a few results before we can prove this part.

Lemma 6.1. In $\Gamma^{\left(k, \epsilon_{b}, \epsilon_{s}\right)}$, the equilibrium strategies of the strategic-type players, $\left(\sigma_{b}, \sigma_{s}\right)$, are such that

1. If $v_{b}>\hat{v}_{b}$, then $\forall t_{b} \in \operatorname{Supp}\left(\sigma_{b}\left(v_{b}\right)\right)$ and $\forall \hat{t}_{b} \in \operatorname{Supp}\left(\sigma_{b}\left(\hat{v}_{b}\right)\right)$, we have $t_{b} \geq \hat{t}_{b}$.

2. If $v_{s}<\hat{v}_{s}$, then $\forall t_{s} \in \operatorname{Supp}\left(\sigma_{s}\left(v_{s}\right)\right)$ and $\forall \hat{t}_{s} \in \operatorname{Supp}\left(\sigma_{s}\left(\hat{v}_{s}\right)\right)$, we have $t_{s} \leq \hat{t}_{s}$. 
Proof: Pick a $v_{b}>\hat{v}_{b}$ and let $t_{b} \in \operatorname{Supp}\left(\sigma_{b}\left(v_{b}\right)\right)$ and $\hat{t}_{b} \in \operatorname{Supp}\left(\sigma_{b}\left(\hat{v}_{b}\right)\right)$. Then the following inequalities are true:

$$
\begin{aligned}
& \left(1-\epsilon_{s}\right) \int_{\left[\underline{t}_{s}, t_{b}\right]}\left(v_{b}-\left(k t_{b}+(1-k) t_{s}\right)\right) d G_{s}+\epsilon_{s} \int_{\left[0, t_{b}\right]}\left(v_{b}-\left(k t_{b}+(1-k) v_{s}\right)\right) d F_{t r_{s}} \geq \\
& \left(1-\epsilon_{s}\right) \int_{\left[\underline{t}_{s}, \hat{t}_{b}\right]}\left(v_{b}-\left(k \hat{t}_{b}+(1-k) t_{s}\right)\right) d G_{s}+\epsilon_{s} \int_{\left[0, \hat{t}_{b}\right]}\left(v_{b}-\left(k \hat{t}_{b}+(1-k) v_{s}\right)\right) d F_{t r_{s}} \\
& (1-\epsilon)_{s} \int_{\left[\underline{t}_{s}, \hat{t}_{b}\right]}\left(\hat{v}_{b}-\left(k \hat{t}_{b}+(1-k) t_{s}\right)\right) d G_{s}+\epsilon_{s} \int_{\left[0, \hat{t}_{b}\right]}\left(\hat{v}_{b}-\left(k \hat{t}_{b}+(1-k) v_{s}\right)\right) d F_{t r_{s}} \geq \\
& \left(1-\epsilon_{s}\right) \int_{\left[\underline{t}_{s}, t_{b}\right]}\left(\hat{v}_{b}-\left(k t_{b}+(1-k) t_{s}\right)\right) d G_{s}+\epsilon_{s} \int_{\left[0, t_{b}\right]}\left(\hat{v}_{b}-\left(k t_{b}+(1-k) v_{s}\right)\right) d F_{t r_{s}}
\end{aligned}
$$

Multiplying (5) by -1 and adding it to (4) we get,

$$
\left(v_{b}-\hat{v}_{b}\right)\left(\left(1-\epsilon_{s}\right) G_{s}\left(t_{b}\right)+\epsilon_{s} F_{t r_{s}}\left(t_{b}\right)\right) \geq\left(v_{b}-\hat{v}_{b}\right)\left(\left(1-\epsilon_{s}\right) G_{s}\left(\hat{t}_{b}\right)+\epsilon_{s} F_{t r_{s}}\left(\hat{t}_{b}\right)\right)
$$

Since $v_{b}>\hat{v}_{b}$, then it must be true that $\left(1-\epsilon_{s}\right) G_{s}\left(t_{b}\right)+\epsilon_{s} F_{t r_{s}}\left(t_{b}\right) \geq\left(1-\epsilon_{s}\right) G_{s}\left(\hat{t}_{b}\right)+\epsilon_{s} F_{t r_{s}}\left(\hat{t}_{b}\right)$. Since $\epsilon_{s}>0$ and $G_{s}$ is non-decreasing and $F_{t r_{s}}$ is strictly increasing on $[0,1]$, it must be that $t_{b} \geq \hat{t}_{b}$

Definition 6.2. For the bilateral trading problem $\left.\left(\left(\epsilon_{b}, \epsilon_{s}\right),\left(F_{s t_{i}}, F_{t r_{i}}\right)_{i=b, s}\right)\right)$, where $F_{s t_{i}}=F_{t r_{i}}$ are uniform on $[0,1], \forall i$, define $\mathcal{M}^{\left(\epsilon_{b}, \epsilon_{s}\right)}$ to be the set of trading outcomes that satisfy $I C^{*}$, $I R$ for the strategic types and

$\mathbf{R} 1 \int_{[0,1]} \int_{[0,1]} x_{(s t, t r)}\left(v_{b}, v_{s}\right) d v_{s} d v_{b}>0$.

$\mathbf{R 2} \int_{[0,1]} \int_{[0,1]} x_{(t r, s t)}\left(v_{b}, v_{s}\right) d v_{s} d v_{b}<1$.

R3 If $v_{b} \geq v_{s}$, then $p_{(t r, t r)}\left(v_{b}, v_{s}\right)=1$; otherwise $p_{(t r, t r)}\left(v_{b}, v_{s}\right)=0$. 
R4 Define, $\bar{p}_{b}\left(v_{b}\right)=\int_{[0,1]} p_{(s t, s t)}\left(v_{b}, v_{s}\right) d v_{s}$ and $\bar{p}_{s}\left(v_{s}\right)=\int_{[0,1]} p_{(s t, s t)}\left(v_{b}, v_{s}\right) d v_{b} . \bar{p}_{b}\left(v_{b}\right)$ is nondecreasing and $\bar{p}_{s}\left(v_{s}\right)$ is non-increasing.

R5 $\int_{[0,1]} \int_{[0,1]} p_{(s t, s t)}\left(v_{b}, v_{s}\right) d v_{s} d v_{b}<\frac{1}{2}$.

Lemma 6.3. Let $M^{\left(\epsilon_{b}, \epsilon_{s}\right)} \in \mathcal{M}^{\left(\epsilon_{b}, \epsilon_{s}\right)}$, where $(0,0) \ll\left(\epsilon_{b}, \epsilon_{s}\right) \ll(1,1)$. There exists $\left(\hat{\epsilon}_{b}, \hat{\epsilon}_{s}\right) \ll$ $\left(\epsilon_{b}, \epsilon_{s}\right)$ and an outcome $M^{\left(\hat{\epsilon}_{b}, \hat{\epsilon}_{s}\right)} \in \mathcal{M}^{\left(\hat{\epsilon}_{b}, \hat{\epsilon}_{s}\right)}$, such that the ex-ante probability of trade in the event that both players are strategic is higher in $M^{\left(\hat{\epsilon}_{b}, \hat{\epsilon}_{s}\right)}$ than in $M^{\left(\epsilon_{b}, \epsilon_{s}\right)}$.

Proof: Let $M^{\left(\epsilon_{b}, \epsilon_{s}\right)}=\left\{\left(p_{(s t, s t)}, p_{(s t, t r)}, p_{(t r, s t)}, p_{(t r, t r)}\right),\left(x_{(s t, s t)}, x_{(s t, t r)}, x_{(t r, s t)}, x_{(t r, t r)}\right)\right\}$. Let $U_{\left(i, d_{i}\right)}\left(v_{i}\right)$ denote the payoff of player $i$ with type $\left(v_{i}, d_{i}\right)$ in this trading outcome. Also, let $P=$ $\int_{[0,1]} \int_{[0,1]} p_{(s t, s t)}\left(v_{b}, v_{s}\right) d v_{s} d v_{b}$.

Pick $\left(\hat{\epsilon}_{b}, \hat{\epsilon}_{s}\right) \ll\left(\epsilon_{b}, \epsilon_{s}\right)$ such that

$$
0<\frac{\left(1-\hat{\epsilon}_{b}\right)\left(1-\hat{\epsilon}_{s}\right) \epsilon_{b} \epsilon_{s}}{\left(1-\epsilon_{b}\right)\left(1-\epsilon_{s}\right) \hat{\epsilon}_{b} \hat{\epsilon}_{s}}-1<\left(\frac{6 \epsilon_{s}}{1-\epsilon_{s}}\right) \int_{[0,1]} \int_{[0,1]} x_{(s t, t r)}\left(v_{b}, v_{s}\right) d v_{s} d v_{b}
$$

Since $P<\frac{1}{2}$ (because $M^{\left(\epsilon_{b}, \epsilon_{s}\right)}$ satisfies R5), we can pick a $\delta>0$ such that

$$
2 P\left(\frac{\left(1-\hat{\epsilon}_{b}\right)\left(1-\hat{\epsilon}_{s}\right) \epsilon_{b} \epsilon_{s}}{\left(1-\epsilon_{b}\right)\left(1-\epsilon_{s}\right) \hat{\epsilon}_{b} \hat{\epsilon}_{s}}-1\right)<\delta \leq \frac{\left(1-\hat{\epsilon}_{b}\right)\left(1-\hat{\epsilon}_{s}\right) \epsilon_{b} \epsilon_{s}}{\left(1-\epsilon_{b}\right)\left(1-\epsilon_{s}\right) \hat{\epsilon}_{b} \hat{\epsilon}_{s}}-1
$$

Define the following $\forall\left(v_{b}, v_{s}\right)$ :

$$
\begin{aligned}
& \hat{p}_{(s t, s t)}\left(v_{b}, v_{s}\right)=\frac{\left(1-\epsilon_{b}\right)\left(1-\epsilon_{s}\right) \hat{\epsilon}_{b} \hat{\epsilon}_{s}}{\left(1-\hat{\epsilon}_{b}\right)\left(1-\hat{\epsilon}_{s}\right) \epsilon_{b} \epsilon_{s}}\left(p_{(s t, s t)}\left(v_{b}, v_{s}\right)+\delta p_{(t r, t r)}\left(v_{b}, v_{s}\right)\right) \\
& \hat{p}_{(s t, t r)}\left(v_{b}, v_{s}\right)=\frac{\left(1-\epsilon_{b}\right) \hat{\epsilon}_{b}}{\left(1-\hat{\epsilon}_{b}\right) \epsilon_{b}} p_{(s t, t r)}\left(v_{b}, v_{s}\right) \\
& \hat{p}_{(t r, s t)}\left(v_{b}, v_{s}\right)=\frac{\left(1-\epsilon_{s}\right) \hat{\epsilon}_{s}}{\left(1-\hat{\epsilon}_{s}\right) \epsilon_{s}} p_{(t r, s t)}\left(v_{b}, v_{s}\right) \\
& \hat{p}_{(t r, t r)}\left(v_{b}, v_{s}\right)=p_{(t r, t r)}\left(v_{b}, v_{s}\right)
\end{aligned}
$$




$$
\begin{aligned}
& \hat{x}_{(s t, s t)}\left(v_{b}, v_{s}\right)=\frac{\left(1-\epsilon_{b}\right)\left(1-\epsilon_{s}\right) \hat{\epsilon}_{b} \hat{\epsilon}_{s}}{\left(1-\hat{\epsilon}_{b}\right)\left(1-\hat{\epsilon}_{s}\right) \epsilon_{b} \epsilon_{s}}\left(x_{(s t, s t)}\left(v_{b}, v_{s}\right)+\delta\left(\frac{v_{b}^{2}-v_{s}^{2}}{2}+\frac{1}{3}\right)\right) \\
& \hat{x}_{(s t, t r)}\left(v_{b}, v_{s}\right)=\frac{\left(1-\epsilon_{b}\right) \hat{\epsilon}_{b}}{\left(1-\hat{\epsilon}_{b}\right) \epsilon_{b}}\left(x_{(s t, t r)}\left(v_{b}, v_{s}\right)-\delta\left(\frac{1-\epsilon_{s}}{6 \epsilon_{s}}\right)\right) \\
& \hat{x}_{(t r, s t)}\left(v_{b}, v_{s}\right)=\frac{\left(1-\epsilon_{s}\right) \hat{\epsilon}_{s}}{\left(1-\hat{\epsilon}_{s}\right) \epsilon_{s}} x_{(t r, s t)}\left(v_{b}, v_{s}\right) \\
& \hat{x}_{(t r, t r)}\left(v_{b}, v_{s}\right)=x_{(t r, t r)}\left(v_{b}, v_{s}\right),
\end{aligned}
$$

Note that $\hat{p}_{(s t, s t)}\left(v_{b}, v_{s}\right) \leq 1$ since $\delta \leq \frac{\left(1-\hat{\epsilon}_{b}\right)\left(1-\hat{\epsilon}_{s}\right) \epsilon_{b} \epsilon_{s}}{\left(1-\epsilon_{b}\right)\left(1-\epsilon_{s}\right) \hat{\epsilon}_{b} \hat{\epsilon}_{s}}-1$.

Let $M^{\left(\hat{\epsilon}_{b}, \hat{\epsilon}_{s}\right)}=\left\{\left(\hat{p}_{(s t, s t)}, \hat{p}_{(s t, t r)}, \hat{p}_{(t r, s t)}, \hat{p}_{(t r, t r)}\right),\left(\hat{x}_{(s t, s t)}, \hat{x}_{(s t, t r)}, \hat{x}_{(t r, s t)}, \hat{x}_{(t r, t r)}\right)\right\}$. Let $\hat{U}_{\left(i, d_{i}\right)}\left(v_{i}\right)$ denote the payoff of player $i$ with type $\left(v_{i}, d_{i}\right)$ in this trading outcome.

For all $v_{b}$ and $v_{s}$, we now have

$$
\begin{aligned}
& \overline{\hat{p}}_{(b, s t)}\left(v_{b}\right)=\frac{\left(1-\epsilon_{b}\right) \hat{\epsilon}_{b} \hat{\epsilon}_{s}}{\left(1-\hat{\epsilon}_{b}\right) \epsilon_{b} \epsilon_{s}}\left(\bar{p}_{(b, s t)}\left(v_{b}\right)+\delta\left(1-\epsilon_{s}\right) v_{b}\right) \\
& \overline{\hat{x}}_{(b, s t)}\left(v_{b}\right)=\frac{\left(1-\epsilon_{b}\right) \hat{\epsilon}_{b} \hat{\epsilon}_{s}}{\left(1-\hat{\epsilon}_{b}\right) \epsilon_{b} \epsilon_{s}}\left(\bar{x}_{(b, s t)}\left(v_{b}\right)+\delta\left(1-\epsilon_{s}\right) \frac{v_{b}^{2}}{2}\right) \\
& \overline{\hat{p}}_{(s, s t)}\left(v_{s}\right)=\frac{\left(1-\epsilon_{s}\right) \hat{\epsilon}_{b} \hat{\epsilon}_{s}}{\left(1-\hat{\epsilon}_{s}\right) \epsilon_{b} \epsilon_{s}}\left(\bar{p}_{(s, s t)}\left(v_{s}\right)+\delta\left(1-\epsilon_{b}\right)\left(1-v_{s}\right)\right) \\
& \overline{\hat{x}}_{(s, s t)}\left(v_{s}\right)=\frac{\left(1-\epsilon_{s}\right) \hat{\epsilon}_{b} \hat{\epsilon}_{s}}{\left(1-\hat{\epsilon}_{s}\right) \epsilon_{b} \epsilon_{s}}\left(\bar{x}_{(s, s t)}\left(v_{s}\right)+\delta\left(1-\epsilon_{b}\right)\left(\frac{1-v_{s}^{2}}{2}\right)\right)
\end{aligned}
$$

We first check that $M^{\left(\hat{\epsilon}_{b}, \hat{\epsilon}_{s}\right)}$ satisfies $I C^{*}$. For all $v_{b}$ and $v_{b}^{\prime}$,

$$
\begin{aligned}
& v_{b} \overline{\hat{p}}_{(b, s t)}\left(v_{b}\right)-\overline{\hat{x}}_{(b, s t)}\left(v_{b}\right)-v_{b} \overline{\hat{p}}_{(b, s t)}\left(v_{b}^{\prime}\right)+\overline{\hat{x}}_{(b, s t)}\left(v_{b}^{\prime}\right) \\
& =\frac{\left(1-\epsilon_{b}\right) \hat{\epsilon}_{b} \hat{\epsilon}_{s}}{\left(1-\hat{\epsilon}_{b}\right) \epsilon_{b} \epsilon_{s}}\left(v_{b} \bar{p}_{(b, s t)}\left(v_{b}\right)-\bar{x}_{(b, s t)}\left(v_{b}\right)-v_{b} \bar{p}_{(b, s t)}\left(v_{b}^{\prime}\right)+\bar{x}_{(b, s t)}\left(v_{b}^{\prime}\right)+\frac{\delta\left(1-\epsilon_{s}\right)}{2}\left(v_{b}-v_{b}^{\prime}\right)^{2}\right) \\
& \geq 0 .
\end{aligned}
$$


Also, for all $v_{s}$ and $v_{s}^{\prime}$,

$$
\begin{aligned}
& \overline{\hat{x}}_{(s, s t)}\left(v_{s}\right)-v_{s} \overline{\hat{p}}_{(s, s t)}\left(v_{s}\right)-\overline{\hat{x}}_{(s, s t)}\left(v_{s}^{\prime}\right)+v_{s} \overline{\hat{p}}_{(s, s t)}\left(v_{s}^{\prime}\right) \\
& =\frac{\left(1-\epsilon_{s}\right) \hat{\epsilon}_{b} \hat{\epsilon}_{s}}{\left(1-\hat{\epsilon}_{s}\right) \epsilon_{b} \epsilon_{s}}\left(\bar{x}_{(s, s t)}\left(v_{s}\right)-v_{s} \bar{p}_{(s, s t)}\left(v_{s}\right)-\bar{x}_{(s, s t)}\left(v_{s}^{\prime}\right)+v_{s} \bar{p}_{(s, s t)}\left(v_{s}^{\prime}\right)+\frac{\delta\left(1-\epsilon_{b}\right)}{2}\left(v_{s}-v_{s}^{\prime}\right)^{2}\right) \\
& \geq 0
\end{aligned}
$$

Next we check that $M^{\left(\hat{\epsilon}_{b}, \hat{\epsilon}_{s}\right)}$ satisfies $I R$ for the strategic types. For all $v_{b}$, we have $\hat{U}_{(b, s t)}\left(v_{b}\right)=\frac{\left(1-\epsilon_{b}\right) \hat{\epsilon}_{\hat{\epsilon}} \hat{\epsilon}_{s}}{\left(1-\hat{\epsilon}_{b}\right) \epsilon_{b} \epsilon_{s}}\left(U_{(b, s t)}\left(v_{b}\right)+\delta\left(1-\epsilon_{s}\right) \frac{v_{b}^{2}}{2}\right) \geq 0$ and for all $v_{s}$, we have $\hat{U}_{(s, s t)}\left(v_{s}\right)=$ $\frac{\left(1-\epsilon_{s}\right) \hat{\epsilon}_{b} \hat{\epsilon}_{s}}{\left(1-\hat{\epsilon}_{s}\right) \epsilon_{b} \epsilon_{s}}\left(U_{(s, s t)}\left(v_{b}\right)+\delta\left(1-\epsilon_{b}\right) \frac{\left(1-v_{s}\right)^{2}}{2}\right) \geq 0$

Now we check that $M^{\left(\hat{\epsilon}_{b}, \hat{\epsilon}_{s}\right)}$ satisfies R1.

$\int_{[0,1]} \int_{[0,1]} \hat{x}_{(s t, t r)}\left(v_{b}, v_{s}\right) d v_{s} d v_{b}=\frac{\left(1-\epsilon_{b}\right) \hat{\epsilon}_{b}}{\left(1-\hat{\epsilon}_{b}\right) \epsilon_{b}}\left(\int_{[0,1]} \int_{[0,1]} x_{(s t, t r)}\left(v_{b}, v_{s}\right) d v_{s} d v_{b}-\delta\left(\frac{1-\epsilon_{s}}{6 \epsilon_{s}}\right)\right)>0$

because (6) and (7) imply that $\delta<\left(\frac{6 \epsilon_{s}}{1-\epsilon_{s}}\right) \int_{[0,1]} \int_{[0,1]} x_{(s t, t r)}\left(v_{b}, v_{s}\right) d v_{s} d v_{b}$.

It is straightforward to check that $M^{\left(\hat{\epsilon}_{b}, \hat{\epsilon}_{s}\right)}$ satisfies R2, R3 and R4.

We finally check that $M^{\left(\hat{\epsilon}_{b}, \hat{\epsilon}_{s}\right)}$ satisfies R5.

$$
\int_{[0,1]} \int_{[0,1]} \hat{p}_{(s t, s t)}\left(v_{b}, v_{s}\right) d v_{s} d v_{b}<\frac{1}{2} \frac{\left(1-\epsilon_{b}\right)\left(1-\epsilon_{s}\right) \hat{\epsilon}_{b} \hat{\epsilon}_{s}}{\left(1-\hat{\epsilon}_{b}\right)\left(1-\hat{\epsilon}_{s}\right) \epsilon_{b} \epsilon_{s}}(1+\delta) \leq \frac{1}{2}
$$

where the first inequality uses the fact that $P<\frac{1}{2}$ and the second inequality uses (7). Therefore, $M^{\left(\hat{\epsilon}_{b}, \hat{\epsilon}_{s}\right)} \in \mathcal{M}^{\left(\hat{\epsilon}_{b}, \hat{\epsilon}_{s}\right)}$.

Lastly, note that

$$
\int_{[0,1]} \int_{[0,1]} \hat{p}_{(s t, s t)}\left(v_{b}, v_{s}\right) d v_{s} d v_{b}=\frac{\left(1-\epsilon_{b}\right)\left(1-\epsilon_{s}\right) \hat{\epsilon}_{b} \hat{\epsilon}_{s}}{\left(1-\hat{\epsilon}_{b}\right)\left(1-\hat{\epsilon}_{s}\right) \epsilon_{b} \epsilon_{s}}\left(P+\frac{\delta}{2}\right)>P
$$

where the inequality follows from $(7)$.

Suppose there exists an $\left(\epsilon_{b}, \epsilon_{s}\right)$ and an equilibrium of $\Gamma^{\left(k, \epsilon_{b}, \epsilon_{s}\right)}$ which has at least as high 
ex-ante probability of trade in the event that both players are strategic than $\frac{9}{32}$. Consider the outcome of that equilibrium, $M^{\left(\epsilon_{b}, \epsilon_{s}\right)}$.

Lemma 6.4. $M^{\left(\epsilon_{b}, \epsilon_{s}\right)} \in \mathcal{M}^{\left(\epsilon_{b}, \epsilon_{s}\right)}$.

Proof: It is straightforward to check that $M^{\left(\epsilon_{b}, \epsilon_{s}\right)}$ will satisfy $I C^{*}$ and $I R$ for the strategic types. It must be that a positive measure of valuation types of the strategic-type buyer submit positive bids. If not, then almost all valuation types of the strategic-type seller will not trade with the strategic-type buyer because the strategic-type seller who trades with a positive probability will bid at least as high as her valuation. This would then contradict the fact that the ex-ante probability of trade among the strategic types is positive. Since a positive measure of valuation types of the strategic-type buyer bid a positive amount and the trustworthy-type seller bids equal to her valuation, R1 is satisfied. R2 is satisfied since $k \in(0,1)$ and the trustworthy-type buyer bids equal to her valuation. R3 is clearly satisfied since the trustworthy types bid equal to their valuations. R4 follows from Lemma 6.1. All valuation types of the strategic-type buyer (seller) who are trading with a positive probability must be bidding at most (least) equal to their respective valuations. Therefore, the ex-ante probability of trade among the strategic types in $M^{\left(\epsilon_{b}, \epsilon_{s}\right)}$ cannot be higher than $\frac{1}{2}$. If the ex-ante probability of trade among the strategic types in $M^{\left(\epsilon_{b}, \epsilon_{s}\right)}$ is equal to $\frac{1}{2}$, then almost all valuation types of the strategic type-players must be bidding equal to their respective valuations. Proposition 4.5 proves that this is impossible and thus, R5 is also satisfied.

Now, using Lemma 6.3, we can construct a sequence of outcomes, $M^{\left(\epsilon_{b}^{n}, \epsilon_{s}^{n}\right)} \in \mathcal{M}^{\left(\epsilon_{b}^{n}, \epsilon_{s}^{n}\right)}$ with $\epsilon_{i}^{1}=\epsilon_{i} \forall i$ and $(0,0) \ll\left(\epsilon_{b}^{n+1}, \epsilon_{s}^{n+1}\right) \ll\left(\epsilon_{b}^{n}, \epsilon_{s}^{n}\right)$, such that the ex-ante probability of trade in the event that both players are strategic type is greater in $M^{\left(\epsilon_{b}^{n+1}, \epsilon_{s}^{n+1}\right)}$ than in $M^{\left(\epsilon_{b}^{n}, \epsilon_{s}^{n}\right)}$.

Let $M^{\left(\epsilon_{b}^{n}, \epsilon_{s}^{n}\right)}=\left\{\left(p_{(s t, s t)}^{n}, p_{(s t, t r)}^{n}, p_{(t r, s t)}^{n}, p_{(t r, t r)}^{n}\right),\left(x_{(s t, s t)}^{n}, x_{(s t, t r)}^{n}, x_{(t r, s t)}^{n}, x_{(t r, t r)}^{n}\right)\right\}$. Then it must be that $\lim _{n \rightarrow \infty} \int_{[0,1]} \int_{[0,1]} p_{(s t, s t)}^{n}\left(v_{b}, v_{s}\right) d v_{b} d v_{s}>\frac{9}{32}$. Moreover, since the sequence of these probabilities is increasing, there exists a $N$ and a small enough $\phi>0$ such that for all $n \geq N, \int_{[0,1]} \int_{[0,1]} p_{(s t, s t)}^{n}\left(v_{b}, v_{s}\right) d v_{b} d v_{s} \geq \frac{9}{32}+\phi$. 
Let $X=\left\{\left(v_{b}, v_{s}\right) \mid 0 \leq v_{b}, v_{s} \leq 1,2 v_{b}-2 v_{s}-1 \geq 0\right\}$ and $I_{X}\left(v_{b}, v_{s}\right)$ be the indicator function that takes the value 1 in the set $X$ and 0 otherwise. Define the following:

$$
\begin{aligned}
q_{\theta}^{n}\left(v_{b}, v_{s}\right) & =(1-\theta) p_{(s t, s t)}^{n}\left(v_{b}, v_{s}\right)+\theta I_{X}\left(v_{b}, v_{s}\right), \theta \in(0,1) \\
\bar{q}_{(b, \theta)}^{n}\left(v_{b}\right) & =\int_{[0,1]} q_{\theta}^{n}\left(v_{b}, v_{s}\right) d v_{s} \\
\bar{q}_{(s, \theta)}^{n}\left(v_{s}\right) & =\int_{[0,1]} q_{\theta}^{n}\left(v_{b}, v_{s}\right) d v_{b} .
\end{aligned}
$$

Note that,

$$
\begin{aligned}
\int_{[0,1]} \int_{[0,1]} q_{\theta}^{n}\left(v_{b}, v_{s}\right) d v_{b} d v_{s} & =(1-\theta) \int_{[0,1]} \int_{[0,1]} p_{(s t, s t)}^{n}\left(v_{b}, v_{s}\right) d v_{b} d v_{s}+\theta \int_{[0,1]} \int_{[0,1]} I_{X} d v_{b} d v_{s} \\
& =(1-\theta) \int_{[0,1]} \int_{[0,1]} p_{(s t, s t)}^{n}\left(v_{b}, v_{s}\right) d v_{b} d v_{s}+\frac{1}{8} \theta
\end{aligned}
$$

Hence there exists a $\hat{\theta}>0$ such that for all $n \geq N$ and $\theta<\hat{\theta}$, we have

$$
\int_{[0,1]} \int_{[0,1]} q_{\theta}^{n}\left(v_{b}, v_{s}\right) d v_{b} d v_{s}=(1-\theta) \int_{[0,1]} \int_{[0,1]} p_{(s t, s t)}^{n}\left(v_{b}, v_{s}\right) d v_{b} d v_{s}+\frac{1}{8} \theta>\frac{9}{32}
$$

We show that there exists a $n^{*} \geq N$ and $\theta^{*}<\hat{\theta}$ such that $\bar{q}_{\left(b, \theta^{*}\right)}^{n^{*}}\left(v_{b}\right)$ is non-decreasing, $\bar{q}_{\left(s, \theta^{*}\right)}^{n^{*}}\left(v_{s}\right)$ is non-increasing and $\int_{[0,1]} \int_{[0,1]}\left(2 v_{b}-2 v_{s}-1\right) q_{\theta^{*}}^{n^{*}}\left(v_{b}, v_{s}\right) d v_{b} d v_{s} \geq 0$. Then, Myerson and Satterthwaite [15, Theorem1] will imply that there exists a $x\left(v_{b}, v_{s}\right)$ such that $q_{\theta^{*}}^{n^{*}}\left(v_{b}, v_{s}\right)$ along with $x\left(v_{b}, v_{s}\right)$ is an incentive compatible and individually rational direct mechanism for the bilateral trading problem in which both players are only strategic type and the valuations of the players are distributed uniformly and independently on $[0,1]$. However, $\int_{[0,1]} \int_{[0,1]} q_{\theta^{*}}^{n^{*}}\left(v_{b}, v_{s}\right) d v_{b} d v_{s}>\frac{9}{32}$, which will contradict the fact that the outcome of the C-S equilibrium has the maximum ex-ante probability of trade in that trading problem.

Since $M^{\left(\epsilon_{b}^{n}, \epsilon_{s}^{n}\right)}$ satisfies R4, $\bar{p}_{b}^{n}\left(v_{b}\right)$ is a non-decreasing while $\bar{p}_{s}^{n}\left(v_{s}\right)$ is non-increasing. This is sufficient to show that $\bar{q}_{(b, \theta)}^{n}\left(v_{b}\right)$ is non-decreasing and $\bar{q}_{(s, \theta)}^{n}\left(v_{s}\right)$ is non-increasing for all $n$ 
and $\theta$.

If there exists a $\hat{n} \geq N$ such that $\int_{[0,1]} \int_{[0,1]}\left(2 v_{b}-2 v_{s}-1\right) p_{(s t, s t)}^{\hat{n}}\left(v_{b}, v_{s}\right) d v_{b} d v_{s} \geq 0$, then take $n^{*}=\hat{n}$ and $\theta^{*}=0$ and we are done.

So suppose that $\forall n \geq N, \int_{[0,1]} \int_{[0,1]}\left(2 v_{b}-2 v_{s}-1\right) p_{(s t, s t)}^{n}\left(v_{b}, v_{s}\right) d v_{b} d v_{s}<0$. For all $n \geq N$, define $\theta(n)$ to be such that

$$
\begin{aligned}
& \int_{[0,1]} \int_{[0,1]}\left(2 v_{b}-2 v_{s}-1\right) q_{\theta(n)}^{n}\left(v_{b}, v_{s}\right) d v_{b} d v_{s} \\
& =(1-\theta(n)) \int_{[0,1]} \int_{[0,1]}\left(2 v_{b}-2 v_{s}-1\right) p_{(s t, s t)}^{n}\left(v_{b}, v_{s}\right) d v_{b} d v_{s}+\frac{1}{24} \theta(n)=0 .
\end{aligned}
$$

Since $M^{\left(\epsilon_{b}^{n}, \epsilon_{s}^{n}\right)}$ satisfies $I C^{*}$ and $I R$ for the strategic types, we get the following inequality using (1) in Lemma 2.5:

$$
\begin{aligned}
& \left(1-\epsilon_{b}^{n}\right)\left(1-\epsilon_{s}^{n}\right) \int_{[0,1]} \int_{[0,1]}\left(2 v_{b}-2 v_{s}-1\right) p_{(s t, s t)}^{n}\left(v_{b}, v_{s}\right) d v_{b} d v_{s} \\
& +\left(1-\epsilon_{b}^{n}\right) \epsilon_{s}^{n} \int_{[0,1]} \int_{[0,1]}\left(2 v_{b}-v_{s}-1\right) p_{(s t, t r)}^{n}\left(v_{b}, v_{s}\right) d v_{b} d v_{s} \\
& +\left(1-\epsilon_{s}^{n}\right) \epsilon_{b}^{n} \int_{[0,1]} \int_{[0,1]}\left(v_{b}-2 v_{s}\right) p_{(t r, s t)}^{n}\left(v_{b}, v_{s}\right) d v_{b} d v_{s} \\
& +\epsilon_{b}^{n} \epsilon_{s}^{n} \int_{[0,1]} \int_{[0,1]}\left(v_{b}-v_{s}\right) p_{(t r, t r)}^{n}\left(v_{b}, v_{s}\right) d v_{b} d v_{s} \\
& \geq \epsilon_{b}^{n} \int_{[0,1]} U_{(b, t r)}^{n}\left(v_{b}\right) d v_{b}+\epsilon_{s}^{n} \int_{[0,1]} U_{(s, t r)}^{n}\left(v_{s}\right) d v_{s} .
\end{aligned}
$$

If $\int_{[0,1]} \int_{[0,1]} x_{(s t, t r)}^{n}\left(v_{b}, v_{s}\right) d v_{s} d v_{b}$ is bounded from below and $\int_{[0,1]} \int_{[0,1]} x_{(t r, s t)}^{n}\left(v_{b}, v_{s}\right) d v_{s} d v_{b}$ is bounded from above, then $\lim _{n \rightarrow \infty} \epsilon_{b}^{n} \int_{[0,1]} U_{(b, t r)}^{n}\left(v_{b}\right) d v_{b}+\epsilon_{s}^{n} \int_{[0,1]} U_{(s, t r)}^{n}\left(v_{s}\right) d v_{s} \geq 0$. This is indeed true because of R1 and R2. Thus, taking the limit of the above expression as $n \rightarrow \infty$, we get $\lim _{n \rightarrow \infty} \int_{[0,1]} \int_{[0,1]}\left(2 v_{b}-2 v_{s}-1\right) p_{(s t, s t)}^{n}\left(v_{b}, v_{s}\right) d v_{b} d v_{s} \geq 0$. Therefore, it must be the case that $\theta(n) \rightarrow 0$. Now, pick $n^{*} \geq N$ to be such that $\theta\left(n^{*}\right)<\hat{\theta}$. Let $\theta^{*}=\theta\left(n^{*}\right)$ and we are done. 
Proof of Proposition 3.2: Define the following $\forall\left(v_{b}, v_{s}\right)$ :

$$
\begin{aligned}
& p_{(s t, s t)}^{\prime}\left(v_{b}, v_{s}\right)=p_{(s t, s t)}\left(v_{b}, v_{s}\right) \\
& p_{(s t, t r)}^{\prime}\left(v_{b}, v_{s}\right)=\frac{\epsilon_{s}\left(1-\epsilon_{s}^{\prime}\right)}{\epsilon_{s}^{\prime}\left(1-\epsilon_{s}\right)} p_{(s t, t r)}\left(v_{b}, v_{s}\right) \leq p_{(s t, t r)}\left(v_{b}, v_{s}\right) \\
& p_{(t r, s t)}^{\prime}\left(v_{b}, v_{s}\right)=\frac{\epsilon_{b}\left(1-\epsilon_{b}^{\prime}\right)}{\epsilon_{b}^{\prime}\left(1-\epsilon_{b}\right)} p_{(t r, s t)}\left(v_{b}, v_{s}\right) \leq p_{(t r, s t)}\left(v_{b}, v_{s}\right) \\
& p_{(t r, t r)}^{\prime}\left(v_{b}, v_{s}\right)=\frac{\epsilon_{s} \epsilon_{b}\left(1-\epsilon_{b}^{\prime}\right)\left(1-\epsilon_{s}^{\prime}\right)}{\epsilon_{s}^{\prime} \epsilon_{b}^{\prime}\left(1-\epsilon_{b}\right)\left(1-\epsilon_{s}\right)} p_{(t r, t r)}\left(v_{b}, v_{s}\right) \leq p_{(t r, t r)}\left(v_{b}, v_{s}\right) \\
& x_{(s t, s t)}^{\prime}\left(v_{b}, v_{s}\right)=x_{(s t, s t)}\left(v_{b}, v_{s}\right) \\
& x_{(s t, t r)}^{\prime}\left(v_{b}, v_{s}\right)=\frac{\epsilon_{s}\left(1-\epsilon_{s}^{\prime}\right)}{\epsilon_{s}^{\prime}\left(1-\epsilon_{s}\right)} x_{(s t, t r)}\left(v_{b}, v_{s}\right) \\
& x_{(t r, s t)}^{\prime}\left(v_{b}, v_{s}\right)=\frac{\epsilon_{b}\left(1-\epsilon_{b}^{\prime}\right)}{\epsilon_{b}^{\prime}\left(1-\epsilon_{b}\right)} x_{(t r, s t)}\left(v_{b}, v_{s}\right) \\
& x_{(t r, t r)}^{\prime}\left(v_{b}, v_{s}\right)=\frac{\epsilon_{s} \epsilon_{b}\left(1-\epsilon_{b}^{\prime}\right)\left(1-\epsilon_{s}^{\prime}\right)}{\epsilon_{s}^{\prime} \epsilon_{b}^{\prime}\left(1-\epsilon_{b}\right)\left(1-\epsilon_{s}\right)} x_{(t r, t r)}\left(v_{b}, v_{s}\right)
\end{aligned}
$$

It follows that

$$
\begin{aligned}
\bar{p}_{(s, s t)}^{\prime}\left(v_{s}\right) & =\left(1-\epsilon_{b}^{\prime}\right) \int_{\left[\underline{a}_{b}, \bar{a}_{b}\right]} p_{(s t, s t)}\left(v_{b}, v_{s}\right) f_{s t_{b}} d v_{b}+\epsilon_{b}^{\prime} \int_{\left[\underline{a}_{b}, \bar{a}_{b}\right]} \frac{\epsilon_{b}\left(1-\epsilon_{b}^{\prime}\right)}{\epsilon_{b}^{\prime}\left(1-\epsilon_{b}\right)} p_{(t r, s t)}\left(v_{b}, v_{s}\right) f_{t r_{b}} d v_{b} \\
& =\frac{1-\epsilon_{b}^{\prime}}{1-\epsilon_{b}}\left(\left(1-\epsilon_{b}\right) \int_{\left[\underline{a}_{b}, \bar{a}_{b}\right]} p_{(s t, s t)}\left(v_{b}, v_{s}\right) f_{s t_{b}} d v_{b}+\epsilon_{b} \int_{\left[\underline{a}_{b}, \bar{a}_{b}\right]} p_{(t r, s t)}\left(v_{b}, v_{s}\right) f_{t r_{b}} d v_{b}\right) \\
& =\frac{1-\epsilon_{b}^{\prime}}{1-\epsilon_{b}} \bar{p}_{(s, s t)}\left(v_{s}\right) .
\end{aligned}
$$

Similarly, $\bar{p}_{(b, s t)}^{\prime}\left(v_{b}\right)=\frac{1-\epsilon_{s}^{\prime}}{1-\epsilon_{s}} \bar{p}_{(b, s t)}\left(v_{b}\right), \bar{x}_{(b, s t)}^{\prime}\left(v_{b}\right)=\frac{1-\epsilon_{s}^{\prime}}{1-\epsilon_{s}} \bar{x}_{(b, s t)}\left(v_{b}\right)$ and $\bar{x}_{(s, s t)}\left(v_{s}\right)=\frac{1-\epsilon_{b}^{\prime}}{1-\epsilon_{b}} \bar{x}_{(s, s t)}\left(v_{s}\right)$. Therefore, $U_{(b, s t)}^{\prime}\left(v_{b}\right)=\frac{1-\epsilon_{s}^{\prime}}{1-\epsilon_{s}} U_{(b, s t)}\left(v_{b}\right)$ and $U_{(s, s t)}^{\prime}\left(v_{s}\right)=\frac{1-\epsilon_{b}^{\prime}}{1-\epsilon_{b}} U_{(s, s t)}\left(v_{s}\right)$. Hence, $\left(p_{\left(d_{b}, d_{s}\right)}^{\prime}, x_{\left(d_{b}, d_{s}\right)}^{\prime}\right)$ satisfies $I C^{*}$ and $I R$ for the strategic types.

It is straightforward to show that $\bar{p}_{(i, t r)}^{\prime}\left(v_{i}\right)=\frac{\epsilon_{i}\left(1-\epsilon_{b}^{\prime}\right)\left(1-\epsilon_{s}^{\prime}\right)}{\epsilon_{i}^{\prime}\left(1-\epsilon_{b}\right)\left(1-\epsilon_{s}\right)} \bar{p}_{(i, t r)}\left(v_{i}\right)$ and $\bar{x}^{\prime}{ }_{(i, t r)}\left(v_{i}\right)=$ $\frac{\epsilon_{i}\left(1-\epsilon_{b}^{\prime}\right)\left(1-\epsilon_{s}^{\prime}\right)}{\epsilon_{i}^{\prime}\left(1-\epsilon_{b}\right)\left(1-\epsilon_{s}\right)} \bar{x}_{(i, t r)}\left(v_{i}\right), i=b, s$. Therefore, $U_{(i, t r)}^{\prime}\left(v_{i}\right)=\frac{\epsilon_{i}\left(1-\epsilon_{b}^{\prime}\right)\left(1-\epsilon_{s}^{\prime}\right)}{\epsilon_{i}^{\prime}\left(1-\epsilon_{b}\right)\left(1-\epsilon_{s}\right)} U_{(i, t r)}\left(v_{i}\right)$. Thus, $\left(p_{\left(d_{b}, d_{s}\right)}^{\prime}, x_{\left(d_{b}, d_{s}\right)}^{\prime}\right)$ also satisfies $I R$ for the trustworthy types. 
Finally, to prove that no strategic type will misreport herself as trustworthy type, note that for all $v_{b}$ and $v_{b}^{\prime}$

$$
\begin{aligned}
U_{(b, s t)}^{\prime}\left(v_{b}\right) & =\frac{1-\epsilon_{s}^{\prime}}{1-\epsilon_{s}} U_{(b, s t)}\left(v_{b}\right) \\
& \geq \frac{1-\epsilon_{s}^{\prime}}{1-\epsilon_{s}}\left(v_{b} \bar{p}_{(b, t r)}\left(v_{b}^{\prime}\right)-\bar{x}_{(b, t r)}\left(v_{b}^{\prime}\right)\right) \\
& =\frac{\epsilon_{b}^{\prime}\left(1-\epsilon_{b}\right)}{\epsilon_{b}\left(1-\epsilon_{b}^{\prime}\right)}\left(v_{b} \bar{p}_{(b, t r)}^{\prime}\left(v_{b}^{\prime}\right)-\bar{x}_{(b, t r)}\left(v_{b}^{\prime}\right)\right) \\
& \geq v_{b} \bar{p}_{(b, t r)}^{\prime}\left(v_{b}^{\prime}\right)-\bar{x}_{(b, t r)}\left(v_{b}^{\prime}\right),
\end{aligned}
$$

where the first inequality follows from the assumption that $\left(p_{\left(d_{b}, d_{s}\right)}, x_{\left(d_{b}, d_{s}\right)}\right)$ satisfies $I C$. Similarly, it is easy to show that $U_{(s, s t)}^{\prime}\left(v_{s}\right) \geq{\overline{x^{\prime}}}_{(s, t r)}\left(v_{s}^{\prime}\right)-v_{s} \bar{p}_{(s, t r)}^{\prime}\left(v_{s}^{\prime}\right), \forall v_{s}, v_{s}^{\prime}$.

Proof of Proposition 4.4: It is easy to see that the functions $p_{(s t, s t)}, p_{(s t, t r)}, p_{(t r, s t)}, p_{(t r, t r)}$ satisfying $E X$ are such that $\bar{p}_{(b, s t)}\left(v_{b}\right)$ is weakly increasing and $\bar{p}_{(s, s t)}\left(v_{s}\right)$ is weakly decreasing. Also, $E X$ implies that

$$
\begin{aligned}
\bar{p}_{(b, s t)}\left(v_{b}\right) & =\left(1-\epsilon_{s}\right) \int_{\left[\underline{a}_{s}, \bar{a}_{s}\right]} p_{(s t, s t)}\left(v_{b}, v_{s}\right) f_{s t_{s}} d v_{s}+\epsilon_{s} \int_{\left[\underline{a}_{s}, \bar{a}_{s}\right]} p_{(s t, t r)}\left(v_{b}, v_{s}\right) f_{t r_{s}} d v_{s} \\
& =\left(1-\epsilon_{s}\right) F_{s t_{s}}\left(v_{b}\right)+\epsilon_{s} F_{t r_{s}}\left(v_{b}\right) \\
& =\left(1-\epsilon_{s}\right) \int_{\left[\underline{a}_{s}, \bar{a}_{s}\right]} p_{(t r, s t)}\left(v_{b}, v_{s}\right) f_{s t_{s}} d v_{s}+\epsilon_{s} \int_{\left[\underline{a}_{s}, \bar{a}_{s}\right]} p_{(t r, t r)}\left(v_{b}, v_{s}\right) f_{t r_{s}} d v_{s} \\
& =\bar{p}_{(b, t r)}\left(v_{b}\right)
\end{aligned}
$$

Since $\bar{p}_{(b, s t)}\left(v_{b}\right)$ is weakly increasing, it follows from the definition of integral that $\forall v_{b}, v_{b}^{\prime}$ such that $v_{b}^{\prime}<v_{b}$,

$$
\int_{\left[\underline{a}_{b}, v_{b}\right]} \bar{p}_{(b, s t)}\left(y_{b}\right) d y_{b} \geq\left(v_{b}-v_{b}^{\prime}\right) \bar{p}_{(b, s t)}\left(v_{b}^{\prime}\right)=\left(v_{b}-v_{b}^{\prime}\right) \bar{p}_{(b, t r)}\left(v_{b}^{\prime}\right)
$$


and $\forall v_{s}, v_{s}^{\prime}$ such that $v_{s}^{\prime}>v_{s}$

$$
\int_{\left[v_{s}, \bar{a}_{s}\right]} \bar{p}_{(s, s t)}\left(y_{s}\right) d y_{s} \geq\left(v_{s}^{\prime}-v_{s}\right) \bar{p}_{(s, s t)}\left(v_{s}^{\prime}\right)=\left(v_{s}^{\prime}-v_{s}\right) \bar{p}_{(s, t r)}\left(v_{s}^{\prime}\right) .
$$

Now, only Inequality (2) is left to be checked. If $\bar{a}_{b} \leq \underline{a}_{s}$, then the left-hand side of (2) equals 0 irrespective of the value of $\epsilon_{b}$ and $\epsilon_{s}$. Hence, in this case $\psi_{i}\left(\epsilon_{i}\right)=0, \forall \epsilon_{i} \in[0,1]$ and $i=b, s$.

So assume that $\bar{a}_{b}>\underline{a}_{s}$. For the functions satisfying $E X$, the left-hand side of (2) is

$$
\begin{aligned}
& \left(1-\epsilon_{b}\right)\left(1-\epsilon_{s}\right) \int_{\left[\underline{a}_{b}, \bar{a}_{b}\right]} \int_{\left[\underline{a}_{s}, \min \left\{v_{b}, \bar{a}_{s}\right\}\right]}\left(\left[v_{b}-\frac{1-F_{s t_{b}}\left(v_{b}\right)}{f_{s t_{b}}\left(v_{b}\right)}\right]-\left[v_{s}+\frac{F_{s t_{s}}\left(v_{s}\right)}{f_{s t_{s}}\left(v_{s}\right)}\right]\right) f_{s t_{s}} f_{s t_{b}} d v_{s} d v_{b} \\
& +\epsilon_{b}\left(1-\epsilon_{s}\right) \int_{\left[\underline{a}_{b}, \bar{a}_{b}\right]} \int_{\left[\underline{a}_{s}, \min \left\{v_{b}, \bar{a}_{s}\right\}\right]}\left(v_{b}-\left[v_{s}+\frac{F_{s t_{s}}\left(v_{s}\right)}{f_{s t_{s}}\left(v_{s}\right)}\right]\right) f_{s t_{s}} f_{t r_{b}} d v_{s} d v_{b} \\
& +\epsilon_{s}\left(1-\epsilon_{b}\right) \int_{\left[\underline{a}_{b}, \bar{a}_{b}\right]} \int_{\left[\underline{a}_{s}, \min \left\{v_{b}, \bar{a}_{s}\right\}\right]}\left(\left[v_{b}-\frac{1-F_{s t_{b}}\left(v_{b}\right)}{f_{s t_{b}}\left(v_{b}\right)}\right]-v_{s}\right) f_{t r_{s}} f_{s t_{b}} d v_{s} d v_{b} \\
& +\epsilon_{b} \epsilon_{s} \int_{\left[\underline{a}_{b}, \bar{a}_{b}\right]} \int_{\left[\underline{a}_{s}, \min \left\{v_{b}, \bar{a}_{s}\right\}\right]}\left(v_{b}-v_{s}\right) f_{t r_{s}} f_{t r_{b}} d v_{s} d v_{b}
\end{aligned}
$$

Myerson and Satterthwaite [15, pg. 272] showed that

$$
\begin{aligned}
& \int_{\left[\underline{a}_{b}, \bar{a}_{b}\right]} \int_{\left[\underline{a}_{s}, \min \left\{v_{b}, \bar{a}_{s}\right\}\right]}\left(\left[v_{b}-\frac{1-F_{s t_{b}}\left(v_{b}\right)}{f_{s t_{b}}\left(v_{b}\right)}\right]-\left[v_{s}+\frac{F_{s t_{s}}\left(v_{s}\right)}{f_{s t_{s}}\left(v_{s}\right)}\right]\right) f_{s t_{s}} f_{s t_{b}} d v_{s} d v_{b} \\
& =-\int_{\left[\underline{a}_{b}, \bar{a}_{s}\right]}\left(1-F_{s t_{b}}(y)\right) F_{s t_{s}}(y) d y
\end{aligned}
$$


Similarly, it is easy to show that

$$
\begin{aligned}
& \int_{\left[\underline{a}_{b}, \bar{a}_{b}\right]} \int_{\left[\underline{a}_{s}, \min \left\{v_{b}, \bar{a}_{s}\right\}\right]}\left(v_{b}-\left[v_{s}+\frac{F_{s t_{s}}\left(v_{s}\right)}{f_{s t_{s}}\left(v_{s}\right)}\right]\right) f_{s t_{s}} f_{t r_{b}} d v_{s} d v_{b} \\
& =\int_{\left[\underline{a}_{b}, \bar{a}_{b}\right]} \int_{\left[\underline{a}_{s}, \min \left\{v_{b}, \bar{a}_{s}\right\}\right]}\left(\left[v_{b}-\frac{1-F_{t r_{b}}\left(v_{b}\right)}{f_{t r_{b}}\left(v_{b}\right)}\right]-\left[v_{s}+\frac{F_{s t_{s}}\left(v_{s}\right)}{f_{s t_{s}}\left(v_{s}\right)}\right]\right) f_{s t_{s}} f_{t r_{b}} d v_{s} d v_{b} \\
& +\int_{\left[\underline{a}_{b}, \bar{a}_{b}\right]} \int_{\left[\underline{a}_{s}, \min \left\{v_{b}, \bar{a}_{s}\right\}\right]}\left(1-F_{t r_{b}}\left(v_{b}\right)\right) f_{s t_{s}} d v_{s} d v_{b} \\
& =-\int_{\left[\underline{a}_{b}, \bar{a}_{s}\right]}\left(1-F_{t r_{b}}(y)\right) F_{s t_{s}}(y) d y+\int_{\left[\underline{a}_{b}\right]}\left(1-F_{t r_{b}}\left(v_{b}\right)\right) F_{s t_{s}}\left(v_{b}\right) d v_{b} \\
& =\int_{\left[\bar{a}_{s}, \bar{a}_{b}\right]}\left(1-F_{t r_{b}}(y)\right) d y \geq 0, \\
& \int_{\left[\underline{a}_{b}, \bar{a}_{b}\right]} \int_{\left[\underline{a}_{s}, \min \left\{v_{b}, \bar{a}_{s}\right\}\right]}\left(\left[v_{b}-\frac{1-F_{s t_{b}}\left(v_{b}\right)}{f_{s t_{b}}\left(v_{b}\right)}\right]-v_{s}\right) f_{t r_{s}} f_{s t_{b}} d v_{s} d v_{b}=\int_{\left[\underline{a}_{s}, \underline{a}_{b}\right]} F_{t r_{s}}(y) d y \geq 0
\end{aligned}
$$

and

$$
\int_{\left[\underline{a}_{b}, \bar{a}_{b}\right]} \int_{\left[\underline{a}_{s}, \min \left\{v_{b}, \bar{a}_{s}\right\}\right]}\left(v_{b}-v_{s}\right) f_{t r_{s}} f_{t r_{b}} d v_{s} d v_{b}=\int_{\left[\underline{a}_{s}, \bar{a}_{b}\right]}\left(1-F_{t r_{b}}(y)\right) F_{t r_{s}}(y) d y \geq 0 .
$$

Define,

$$
\begin{aligned}
\alpha_{(s t, s t)} & =-\int_{\left[\underline{a}_{b}, \bar{a}_{s}\right]}\left(1-F_{s t_{b}}(y)\right) F_{s t_{s}}(y) d y \\
\alpha_{(s t, t r)} & =\int_{\left[\underline{a}_{s}, \underline{a}_{b}\right]} F_{t r_{s}}(y) d y \\
\alpha_{(t r, s t)} & =\int_{\left[\bar{a}_{s}, \bar{a}_{b}\right]}\left(1-F_{t r_{b}}(y)\right) d y \\
\alpha_{(t r, t r)} & =\int_{\left[\underline{a}_{s}, \bar{a}_{b}\right]}\left(1-F_{t r_{b}}(y)\right) F_{t r_{s}}(y) d y
\end{aligned}
$$


Hence (8) can be written as

$$
\left(1-\epsilon_{b}\right)\left(1-\epsilon_{s}\right) \alpha_{(s t, s t)}+\epsilon_{b}\left(1-\epsilon_{s}\right) \alpha_{(t r, s t)}+\left(1-\epsilon_{b}\right) \epsilon_{s} \alpha_{(s t, t r)}+\epsilon_{b} \epsilon_{s} \alpha_{(t r, t r)}
$$

1. $\bar{a}_{s} \leq \underline{a}_{b}$ : In this case, $\alpha_{(s t, s t)} \geq 0$ but $\alpha_{(s t, t r)}, \alpha_{(t r, s t)}$ and $\alpha_{(t r, t r)}$ are positive. Thus, the left-hand side of (2) is positive irrespective of the value of $\epsilon_{b}$ and $\epsilon_{s}$. Therefore, in this case $\psi_{i}\left(\epsilon_{i}\right)=0, \forall \epsilon_{i} \in[0,1]$ and $i=b, s$.

2. $\left[\underline{a}_{b}, \bar{a}_{b}\right] \cap\left[\underline{a}_{s}, \bar{a}_{s}\right]$ has a non-empty interior: In this case, $\alpha_{(s t, s t)}<0, \alpha_{(t r, t r)}>0$ and both $\alpha_{(s t, t r)}$ and $\alpha_{(t r, s t)}$ are non-negative. Define

$$
\psi_{b}\left(\epsilon_{b}\right)=\max \left\{0, \frac{\left(1-\epsilon_{b}\right) \alpha_{(s t, s t)}+\epsilon_{b} \alpha_{(t r, s t)}}{\left(1-\epsilon_{b}\right)\left(\alpha_{(s t, s t)}-\alpha_{(s t, t r)}\right)+\epsilon_{b}\left(\alpha_{(t r, s t)}-\alpha_{(t r, t r)}\right)}\right\}
$$

Note that $\frac{\left(1-\epsilon_{b}\right) \alpha_{(s t, s t)}+\epsilon_{b} \alpha_{(t r, s t)}}{\left(1-\epsilon_{b}\right)\left(\alpha_{(s t, s t)}-\alpha_{(s t, t r)}\right)+\epsilon_{b}\left(\alpha_{(t r, s t)}-\alpha_{(t r, t r)}\right)}$ is a strictly decreasing function of $\epsilon_{b}$ and $0<$ $\psi_{b}(0) \leq 1$. Therefore, $\psi_{b}$ is weakly decreasing and $\psi_{b}\left(\epsilon_{b}\right)<1, \forall \epsilon_{b}>0$.

It is easy to check that for any $\epsilon_{b}$, the expression in (9) is non-negative for all $\epsilon_{s} \geq \psi_{b}\left(\epsilon_{b}\right)$. Also, $\left(\hat{\epsilon}_{b}, \hat{\epsilon}_{s}\right) \geq\left(\epsilon_{b}, \psi_{b}\left(\epsilon_{b}\right)\right) \Longrightarrow\left(\hat{\epsilon}_{b}, \hat{\epsilon}_{s}\right) \geq\left(\hat{\epsilon}_{b}, \psi_{b}\left(\hat{\epsilon}_{b}\right)\right)$ and therefore, the expression in (9) is non-negative for such a $\left(\hat{\epsilon}_{b}, \hat{\epsilon}_{s}\right)$.

Similarly, it is easy to show that

$$
\psi_{s}\left(\epsilon_{s}\right)=\max \left\{0, \frac{\left(1-\epsilon_{s}\right) \alpha_{(s t, s t)}+\epsilon_{s} \alpha_{(s t, t r)}}{\left(1-\epsilon_{s}\right)\left(\alpha_{(s t, s t)}-\alpha_{(t r, s t)}\right)+\epsilon_{s}\left(\alpha_{(s t, t r)}-\alpha_{(t r, t r)}\right)}\right\} .
$$

Proof of Proposition 4.5: Suppose for some $k \in[0,1]$ and $\left(\epsilon_{b}, \epsilon_{s}\right) \ll(1,1)$, there exists an equilibrium of the $k$-double auction that satisfies $E X^{*}$. Since the strategic-type buyer with $v_{b} \in\left(\underline{a}_{s}, \bar{a}_{s}\right) \cap\left(\underline{a}_{b}, \bar{a}_{b}\right)$ trades with a positive probability, she is not bidding more than her valuation. Similarly, the strategic-type seller with $v_{s} \in\left(\underline{a}_{s}, \bar{a}_{s}\right) \cap\left(\underline{a}_{b}, \bar{a}_{b}\right)$ is not bidding less than her valuation. The strategic-type buyer with $v_{b} \in\left(\underline{a}_{s}, \bar{a}_{s}\right) \cap\left(\underline{a}_{b}, \bar{a}_{b}\right)$ is also not 
bidding a number less than her valuation with a positive probability because in that case, with a positive probability, she would not be able to trade with some valuation-types of the strategic-type seller whose valuations lie in $\left(\underline{a}_{s}, \bar{a}_{s}\right) \cap\left(\underline{a}_{b}, \bar{a}_{b}\right)$ because, as argued above, all valuation-types of the strategic-type seller with valuations in this interval bid at least equal to their respective valuations. Similarly, the strategic-type seller with $v_{s} \in\left(\underline{a}_{s}, \bar{a}_{s}\right) \cap\left(\underline{a}_{b}, \bar{a}_{b}\right)$ is not bidding a number more than her valuation with a positive probability. Thus, the strategic-type player with $v_{i} \in\left(\underline{a}_{s}, \bar{a}_{s}\right) \cap\left(\underline{a}_{b}, \bar{a}_{b}\right)$ is bidding equal to her valuation.

Case 1: $k<1$. We provide a contradiction by showing that for the strategic seller with $v_{s} \in\left(\underline{a}_{s}, \bar{a}_{s}\right) \cap\left(\underline{a}_{b}, \bar{a}_{b}\right), \exists t_{s}>v_{s}$ such that the payoff from bidding $t_{s}$ is strictly higher than the payoff from bidding $v_{s}$. Consider the difference in these payoffs,

$$
\begin{aligned}
& \left(1-\epsilon_{b}\right) \int_{\left[t_{s}, \bar{t}_{b}\right]}\left(k t_{b}+(1-k) t_{s}-v_{s}\right) d G_{b}+\epsilon_{b} \int_{\left[t_{s}, \bar{a}_{b}\right]}\left(k v_{b}+(1-k) t_{s}-v_{s}\right) d F_{t r_{b}} \\
& -\left(1-\epsilon_{b}\right) \int_{\left(v_{s}, \bar{t}_{b}\right]}\left(k t_{b}+(1-k) v_{s}-v_{s}\right) d G_{b}-\epsilon_{b} \int_{\left(v_{s}, \bar{a}_{b}\right]}\left(k v_{b}+(1-k) v_{s}-v_{s}\right) d F_{t r_{b}} \\
& =(1-k) \int_{\left[t_{s}, \bar{t}_{b}^{\prime}\right]}\left(t_{s}-v_{s}\right) d G_{b}^{\prime}-k \int_{\left(v_{s}, t_{s}\right)}\left(t_{b}-v_{s}\right) d G_{b}^{\prime} \\
& \geq\left(t_{s}-v_{s}\right)\left((1-k) \int_{\left[t_{s}, \bar{t}_{b}^{\prime}\right]} d G_{b}^{\prime}-k \int_{\left(v_{s}, t_{s}\right)} d G_{b}^{\prime}\right)
\end{aligned}
$$

where $G_{b}^{\prime}\left(v_{b}\right)=\left(1-\epsilon_{b}\right) G_{b}\left(v_{b}\right)+\epsilon_{b} F_{t r_{b}}\left(v_{b}\right)$ is the distribution of the buyer's bid and $\bar{t}_{b}{ }_{b}=$ $\inf \left\{t_{b} \mid G_{b}^{\prime}\left(t_{b}\right)=1\right\}$. There must exist a $t_{s}>v_{s}$ such that the last term is positive. If not, then $\lim _{t_{s} \backslash v_{s}}\left((1-k) \int_{\left[t_{s}, \bar{t}_{b}^{\prime}\right]} d G_{b}^{\prime}-k \int_{\left(v_{s}, t_{s}\right)} d G_{b}^{\prime}\right)=(1-k)\left(1-G_{b}^{\prime}\left(v_{s}\right)\right) \leq 0$. Then $k<1$ implies that $G_{b}^{\prime}\left(v_{s}\right) \geq 1$. This is not possible since $F_{t r_{b}}\left(v_{s}\right)<1$ because $v_{s} \in\left(\underline{a}_{s}, \bar{a}_{s}\right) \cap\left(\underline{a}_{b}, \bar{a}_{b}\right)$. Case 2: $k>0$. Like the previous case, we can provide a contradiction by showing that for the strategic buyer with $v_{b} \in\left(\underline{a}_{s}, \bar{a}_{s}\right) \cap\left(\underline{a}_{b}, \bar{a}_{b}\right), \exists t_{b}<v_{b}$ such that the payoff from bidding $t_{b}$ is strictly higher than the payoff from bidding $v_{b}$.

Proof of Proposition 4.7: Let $\left(p_{\left(d_{b}, d_{s}\right)}, x_{\left(d_{b}, d_{s}\right)}\right)_{d_{b}=s t, t r ; d_{s}=s t, t r}$ be a Bayesian-Nash equilibrium outcome of some $k$-double auction with any form of pre-play communication that 
satisfies EX. By Lemma 2.5, it must satisfy (1), which can be re-written as,

$$
\begin{aligned}
& \quad\left(1-\epsilon_{b}\right)\left(1-\epsilon_{s}\right) \int_{\left[\underline{a}_{b}, \bar{a}_{b}\right]} \int_{\left[\underline{a}_{s}, \bar{a}_{s}\right]}\left(\left[v_{b}-\frac{1-F_{s t_{b}}\left(v_{b}\right)}{f_{s t_{b}}\left(v_{b}\right)}\right]-\left[v_{s}+\frac{F_{s t_{s}}\left(v_{s}\right)}{f_{s t_{s}}\left(v_{s}\right)}\right]\right) p_{(s t, s t)}\left(v_{b}, v_{s}\right) f_{s t_{s}} f_{s t_{b}} d v_{s} d v_{b} \\
& +\epsilon_{b}\left(1-\epsilon_{s}\right) \int_{\left[\underline{a}_{b}, \bar{a}_{b}\right]} \int_{\left[\underline{a}_{s}, \bar{a}_{s}\right]}\left(x_{(t r, s t)}\left(v_{b}, v_{s}\right)-\left[v_{s}+\frac{F_{s t_{s}}\left(v_{s}\right)}{f_{s t_{s}}\left(v_{s}\right)}\right] p_{(t r, s t)}\left(v_{b}, v_{s}\right)\right) f_{s t_{s}} f_{t r_{b}} d v_{s} d v_{b} \\
& +\epsilon_{s}\left(1-\epsilon_{b}\right) \int_{\left[\underline{a}_{b}, \bar{a}_{b}\right]} \int_{\left[\underline{a}_{s}, \bar{a}_{s}\right]}\left(\left[v_{b}-\frac{1-F_{s t_{b}}\left(v_{b}\right)}{f_{s t_{b}}\left(v_{b}\right)}\right] p_{(s t, t r)}\left(v_{b}, v_{s}\right)-x_{(s t, t r)}\left(v_{b}, v_{s}\right)\right) f_{t r_{s}} f_{s t_{b}} d v_{s} d v_{b} \\
& =\left(1-\epsilon_{b}\right) U_{(b, s t)}\left(\underline{a}_{b}\right)+\left(1-\epsilon_{s}\right) U_{(s, s t)}\left(\bar{a}_{s}\right)
\end{aligned}
$$

Since the outcome is $E X, p_{\left(d_{b}, d_{s}\right)}\left(v_{b}, v_{s}\right) \in\{0,1\}$. Also, a buyer makes a payment to a seller if and only if they trade, that is, $x_{\left(d_{b}, d_{s}\right)}\left(v_{b}, v_{s}\right)=0$ if $p_{\left(d_{s}, d_{b}\right)}\left(v_{b}, v_{s}\right)=0$. Therefore, $\forall\left(d_{b}, d_{s}\right)$ and $\left(v_{b}, v_{s}\right)$, we have $x_{\left(d_{b}, d_{s}\right)}\left(v_{b}, v_{s}\right)=x_{\left(d_{b}, d_{s}\right)}\left(v_{b}, v_{s}\right) p_{\left(d_{s}, d_{b}\right)}\left(v_{b}, v_{s}\right)$. Finally, $x_{(t r, s t)}\left(v_{b}, v_{s}\right) \leq v_{b}$ and $x_{(s t, t r)}\left(v_{b}, v_{s}\right) \geq v_{s}$. Substituting these in the above equality, we get

$$
\begin{aligned}
& \left(1-\epsilon_{b}\right) U_{(b, s t)}\left(\underline{a}_{b}\right)+\left(1-\epsilon_{s}\right) U_{(s, s t)}\left(\bar{a}_{s}\right) \\
& \leq\left(1-\epsilon_{b}\right)\left(1-\epsilon_{s}\right) \int_{\left[\underline{a}_{b}, \bar{a}_{b}\right]} \int_{\left[\underline{a}_{s}, \bar{a}_{s}\right]}\left(\left[v_{b}-\frac{1-F_{s t_{b}}\left(v_{b}\right)}{f_{s t_{b}}\left(v_{b}\right)}\right]-\left[v_{s}+\frac{F_{s t_{s}}\left(v_{s}\right)}{f_{s t_{s}}\left(v_{s}\right)}\right]\right) p_{(s t, s t)}\left(v_{b}, v_{s}\right) f_{s t_{s}} f_{s t_{b}} d v_{s} d v_{b} \\
& +\epsilon_{b}\left(1-\epsilon_{s}\right) \int_{\left[\underline{a}_{b}, \bar{a}_{b}\right]} \int_{\left[\underline{a}_{s}, \bar{a}_{s}\right]}\left(v_{b}-\left[v_{s}+\frac{F_{s t_{s}}\left(v_{s}\right)}{f_{s t_{s}}\left(v_{s}\right)}\right]\right) p_{(t r, s t)}\left(v_{b}, v_{s}\right) f_{s t_{s}} f_{t r_{b}} d v_{s} d v_{b} \\
& +\epsilon_{s}\left(1-\epsilon_{b}\right) \int_{\left[\underline{a}_{b}, \bar{a}_{b}\right]} \int_{\left[\underline{a}_{s}, \bar{a}_{s}\right]}\left(\left[v_{b}-\frac{1-F_{s t_{b}}\left(v_{b}\right)}{f_{s t_{b}}\left(v_{b}\right)}\right]-v_{s}\right) p_{(s t, t r)}\left(v_{b}, v_{s}\right) f_{t r_{s}} f_{s t_{b}} d v_{s} d v_{b} \\
& =-\left(1-\epsilon_{b}\right)\left(1-\epsilon_{s}\right) \int_{\left[\underline{a}_{b}, \bar{a}_{s}\right]}\left(1-F_{s t_{b}}(y)\right) F_{s t_{s}}(y) d y+\epsilon_{b}\left(1-\epsilon_{s}\right) \int_{\left[\bar{a}_{s}, \bar{a}_{b}\right]}\left(1-F_{t r_{b}}(y)\right) d y \\
& +\left(1-\epsilon_{b}\right) \epsilon_{s} \int_{\left[\underline{a}_{s}, \underline{a}_{b}\right]} F_{t r_{s}}(y) d y \\
& <0
\end{aligned}
$$

where the second step follows from the fact that the outcome satisfies $E X$ (see proof of Proposition 4.4) and the final step uses the fact that $\underline{a}_{b} \leq \underline{a}_{s}$ and $\bar{a}_{b} \leq \bar{a}_{b}$. Therefore, the 
outcome does not satisfy $I R \cdot .^{12}$

\section{References}

[1] D. Abreu, F. Gul, Bargaining and reputation, Econometrica 68 (2000), 85-117.

[2] G. Akerlof, The market for "Lemons": Quality, uncertainty and the market mechanism, Quart. J. Econ. 84 (1970), 488-500.

[3] K. Chatterjee, W. Samuelson, Bargaining under incomplete information, Operations Research 31 (1983), 835-851.

[4] P. Dasgupta, Trust as a commodity, in: D. Gambetta (Ed.), Trust: Making and Breaking Cooperative Relations, Basil Blackwell, Oxford, 1988, pp. 49-72.

[5] J. Farrell, R. Gibbons, Cheap talk can matter in bargaining, J. Econ. Theory 48 (1989), 221-237.

[6] D. Gambetta, Can we trust trust?, in: D. Gambetta (Ed.), Trust: Making and Breaking Cooperative Relations, Basil Blackwell, Oxford, 1988, pp. 213-237.

[7] D. Good, Individuals, interpersonal relations, and trust, in: D. Gambetta (Ed.), Trust: Making and Breaking Cooperative Relations, Basil Blackwell, Oxford, 1988, pp. 31-48.

[8] R. Hardin, Trust and Trustworthiness, Russell Sage Foundation, New York, 2002.

[9] D. Kreps, P. Milgrom, J. Roberts, R. Wilson, Rational cooperation in the finitely repeated Prisoner's Dilemma, J. Econ. Theory 27 (1982), 245-252.

[10] D. Kreps, R. Wilson, Reputation and imperfect information, J. Econ. Theory 27 (1982), 253-279.

\footnotetext{
${ }^{12}$ If either $\underline{a}_{s}<\underline{a}_{b}$ or $\bar{a}_{s}<\bar{a}_{b}$, then both $\int_{\left[\bar{a}_{s}, \bar{a}_{b}\right]}\left(1-F_{t r_{b}}(y)\right) d y$ and $\int_{\left[\underline{a}_{s}, \underline{a}_{b}\right]} F_{t r_{s}}(y) d y$ are positive and so the last inequality in the proof does not follow.
} 
[11] W. Leininger, P. Linhart, R. Radner, Equilibria of the sealed-bid mechanism for bargaining with incomplete information, J. Econ. Theory 48 (1989), 63-106.

[12] S. Mathews, A. Postlewaite, Pre-play communication in two-person sealed-bid double auctions, J. Econ. Theory 48 (1989), 238-263.

[13] K. McGinn, L. Thompson, M. Bazerman, Dyadic processes of disclosure and reciprocity in bargaining with communication, Journal of Behavioral Decision Making 16 (2003), 17-34.

[14] P. Milgrom, J. Roberts, Predation, reputation and entry deterrence, J. Econ. Theory 27 (1982), 280-312.

[15] R. Myerson, M. Satterthwaite, Efficient mechanisms for bilateral trading, J. Econ. Theory 29 (1983), 265-281.

[16] J. Pearsall (Ed.), The Concise Oxford Dictionary Tenth Edition, Oxford University Press, New Delhi, 1999.

[17] R. Radner, A. Schotter, The sealed-bid mechanism: An experimental study, J. Econ. Theory 48 (1989), 179-220.

[18] R. Saran, R. Serrano, The evolution of bidding behavior in private-values auctions and double auctions, Working Paper 2007-01, Brown University, 2007.

[19] M. Satterthwaite, S. Williams, Bilateral trade with the sealed bid $k$-double auction: Existence and efficiency, J. Econ. Theory 48 (1989), 107-133.

[20] J. Sobel, A theory of credibility, Rev. Econ. Stud. LII (1985), 557-573.

[21] K. Valley, L. Thompson, R. Gibbons, M. Bazerman, How communication improves efficiency in bargaining games, Games Econ. Behav. 38 (2002), 127-155. 